\title{
OPEN Leaf scale quantification of the effect of photosynthetic gas exchange on $\Delta_{47}$ of $\mathrm{CO}_{2}$
}

\author{
Getachew Agmuas Adnew ${ }^{1,6 \bowtie}$, Magdalena E. G. Hofmann ${ }^{1,5,6}$, Thijs L. Pons ${ }^{2}$, \\ Gerbrand Koren ${ }^{3}$, Martin Ziegler ${ }^{4}$, Lucas J. Lourens ${ }^{4}$ \& Thomas Röckmann ${ }^{1}$
}

The clumped isotope composition ( $\Delta_{47,}$ the anomaly of the mass 47 isotopologue relative to the abundance expected from a random isotope distribution) of $\mathrm{CO}_{2}$ has been suggested as an additional tracer for gross $\mathrm{CO}_{2}$ fluxes. However, the effect of photosynthetic gas exchange on $\Delta_{47}$ has not been directly determined and two indirect/conceptual studies reported contradicting results. In this study, we quantify the effect of photosynthetic gas exchange on $\Delta_{47}$ of $\mathrm{CO}_{2}$ using leaf cuvette experiments with one $C_{4}$ and two $C_{3}$ plants. The experimental results are supported by calculations with a leaf cuvette model. Our results demonstrate the important roles of the $\Delta_{47}$ value of $\mathrm{CO}_{2}$ entering the leaf, kinetic fractionation as $\mathrm{CO}_{2}$ diffuses into, and out of the leaf and $\mathrm{CO}_{2}-\mathrm{H}_{2} \mathrm{O}$ isotope exchange with leaf water. We experimentally confirm the previously suggested dependence of $\Delta_{47}$ of $\mathrm{CO}_{2}$ in the air surrounding a leaf on the stomatal conductance and back-diffusion flux. Gas exchange can enrich or deplete the $\Delta_{47}$ of $\mathrm{CO}_{2}$ depending on the $\Delta_{47}$ of $\mathrm{CO}_{2}$ entering the leaf and the fraction of $\mathrm{CO}_{2}$ exchanged with leaf water and diffused back to the atmosphere, but under typical ambient conditions, it will lead to a decrease in $\Delta_{47}$.

The carbon dioxide $\left(\mathrm{CO}_{2}\right)$ concentration in the atmosphere is controlled by various large exchange fluxes with the bio-, hydro- and geosphere, and by anthropogenic emissions. Important tools for quantifying the different terms of the budget are measurement of the mole fraction and the isotopic composition of $\mathrm{CO}_{2}{ }^{1}$. The stable carbon isotope composition allows to distinguish between the $\mathrm{CO}_{2}$ uptake by the ocean and by plants ${ }^{2}$, and the stable oxygen isotope composition allows to determine the magnitude of the large gross carbon fluxes between the atmosphere and biosphere ${ }^{3-6}$. Recent advancements in precise measurement techniques of ${ }^{17} \mathrm{O}$-excess ${ }^{7}$ enable the ${ }^{17} \mathrm{O}$-excess, $\Delta^{17} \mathrm{O}$, of tropospheric $\mathrm{CO}_{2}$ to be used as tracer of terrestrial gross primary production ${ }^{8-13}$ or stratospheric influx ${ }^{14-16}$. In addition, the analysis of radiocarbon has been used to quantify the amount of anthropogenic $\mathrm{CO}_{2}$ emissions ${ }^{17,18}$. Despite these four independent isotopic tracers, the $\mathrm{CO}_{2}$ budget still remains uncertain. It has been suggested that the abundance of the isotopologue ${ }^{18} \mathrm{O}^{13} \mathrm{C}^{16} \mathrm{O}$ in the atmosphere might be a promising new tracer to complement the existing isotope tracers ${ }^{19-23}$.

The abundance of the double substituted (i.e., contain two rare isotopes) isotopologue ${ }^{13} \mathrm{C}^{18} \mathrm{O}^{16} \mathrm{O}$, compared to its abundance at stochastic isotope distribution for a given bulk composition, is also referred to as the clumped isotopic composition of $\mathrm{CO}_{2}\left(\Delta_{47}\right.$, see Sect. "Theory" for definition). One of the main reasons for its applicability as a tracer to constrain $\mathrm{CO}_{2}$ fluxes is that it is mainly sensitive to the temperature at which the $\mathrm{CO}_{2}$ is formed or exchanges isotopes with water ${ }^{19}$. A disadvantage of using $\Delta_{47}$ is that signals are very small: For typical ambient surface temperatures of 5 to $30^{\circ} \mathrm{C}$, the thermodynamic equilibrium value of $\Delta_{47}$ ranges between 0.90 to 1.04 $\%{ }^{19,24,25}$, so high precision measurements are required. Thermodynamic equilibrium values of $\Delta_{47}$ decrease towards 0 at increasingly higher temperatures, and it is possible to distinguish high temperature (e.g. combustion) from low temperature process (e.g. respiration) using $\Delta_{47}^{19,20,22,26}$.

It is well established that oxygen isotope exchange between $\mathrm{CO}_{2}$ and water in the biosphere and hydrosphere is the dominant process controlling the oxygen isotope composition of atmospheric $\mathrm{CO}_{2}{ }^{27,28}$. The $\mathrm{CO}_{2}-\mathrm{H}_{2} \mathrm{O}$ exchange in soils and leaf water is catalyzed by the enzyme carbonic anhydrase $(\mathrm{CA})^{27,29-31}$. In the leaf, $\mathrm{CO}_{2}-\mathrm{H}_{2} \mathrm{O}$ exchange takes place in the mesophyll, and the mole fraction of the $\mathrm{CO}_{2}$ at the $\mathrm{CO}_{2}-\mathrm{H}_{2} \mathrm{O}$ exchange site is expressed as $c_{\mathrm{m}}$ (see Sects. " $\mathrm{CO}_{2}$ exchange fluxes during photosynthesis" and "Mesophyll conductance").

${ }^{1}$ Institute for Marine and Atmospheric Research Utrecht, Utrecht University, Utrecht, The Netherlands. ${ }^{2}$ Institute of Environmental Biology, Utrecht University, Utrecht, The Netherlands. ${ }^{3}$ Meteorology and Air Quality Group, Wageningen University, Wageningen, The Netherlands. 'Department of Earth Sciences, Utrecht University, Utrecht, The Netherlands. ${ }^{5}$ Present address: Picarro B.V., 's-Hertogenbosch, The Netherlands. ${ }^{6}$ These authors contributed equally: Getachew Agmuas Adnew and Magdalena E. G. Hofmann ${ }^{\square}$ email: g.a.adnew@uu.nl 
Laboratory studies have shown that the rate of exchange between $\mathrm{CO}_{2}$ and water is the same for $\delta^{18} \mathrm{O}$ and $\Delta_{47}{ }^{32,33}$. This finding suggests that the equilibration between $\mathrm{CO}_{2}$ and leaf water, soil water or open surface water should affect $\Delta_{47}$ with similar kinetics as $\delta^{18} \mathrm{O}$, but in contrast to $\delta^{18} \mathrm{O}, \Delta_{47}$ does not depend on the isotopic composition of the different water pools. The rapid isotope exchange of $\mathrm{CO}_{2}$ with leaf and surface waters is thought to drive the $\Delta_{47}$ of atmospheric $\mathrm{CO}_{2}$ towards the thermodynamic equilibrium value ${ }^{1,19}$.

Measurements of $\Delta_{47}$ in $\mathrm{CO}_{2}$ from air samples show that the clumped isotopic composition in the atmosphere is not in thermodynamic equilibrium at the global mean air temperature. For instance, background $\mathrm{CO}_{2}$ from remote air observatories shows $\Delta_{47}$ values of $0.92 \% 0^{21}$, which is $0.06 \%$ lower than the expected value of $0.98 \%$ o for a global mean air temperature of $15^{\circ} \mathrm{C}^{34}$. In urban and suburban air, $\Delta_{47}$ values are generally even lower and the variability of the reported $\Delta_{47}$ values was higher, possibly due to input from anthropogenic $\mathrm{CO}_{2}$ formed in high temperature combustion. In Pasadena, Affek and Eiler ${ }^{20}$, Affek, et al. ${ }^{26}$, found $\Delta_{47}$ values between 0.73 and $1.01 \%$, and Eiler and Schauble ${ }^{19}$ reported even lower values between 0.62 and $0.93 \%$ from a similar location. Laskar and Liang ${ }^{22}$ reported $\Delta_{47}$ values between 0.75 and $0.93 \%$ for urban and suburban air in Taiwan.

Eiler and Schauble ${ }^{19}$ developed a conceptual model to mathematically describe the effect of air-leaf interaction on the $\Delta_{47}$ signature of atmospheric $\mathrm{CO}_{2}$. The main assumption is that the carbonic anhydrase catalyzed exchange between $\mathrm{CO}_{2}$ and $\mathrm{H}_{2} \mathrm{O}$ within the mesophyll will imprint a $\Delta_{47}$ value that reflects the effect of leaf temperature on the $\mathrm{CO}_{2}$ that diffuses back out of the stomata to the atmosphere. In addition, kinetic fractionation during the diffusion into and out of the leaf through the stomata affects $\Delta_{47}$ during photosynthetic gas exchange. Eiler and Schauble ${ }^{19}$ proposed that this kinetic isotope fractionation is significant especially for plant species that show a low carbonic anhydrase activity. In this case, the diffusive component during photosynthesis might lead to a depletion in $\Delta_{47}$ of atmospheric $\mathrm{CO}_{2}$ of about $0.1 \%$ relative to the thermodynamic equilibrium value of $\mathrm{CO}_{2}-\mathrm{H}_{2} \mathrm{O}$ exchange alone.

Surprisingly, a recent study, Laskar and Liang ${ }^{22}$ reported $\Delta_{47}$ measurements of $\mathrm{CO}_{2}$ sampled in a greenhouse that show enrichment by up to $0.08 \%$ in $\Delta_{47}$ relative to the thermodynamic equilibrium value. The authors attributed this deviation to kinetic effects associated with the photosynthetic exchange, but as described in Eiler and Schauble ${ }^{19}$, such a kinetic effect should lead to lower, not higher $\Delta_{47}$ values relative to the thermodynamic equilibrium. Furthermore Laskar and Liang ${ }^{22}$ concluded that photosynthetic gas exchange would decouple $\Delta_{47}$ and $\delta^{18} \mathrm{O}$ in contradiction to the simple $\mathrm{CO}_{2}-\mathrm{H}_{2} \mathrm{O}$ exchange model of Eiler and Schauble ${ }^{19}$. This discrepancy calls for controlled air-leaf gas exchange experiments to characterize the effect of photosynthesis on $\Delta_{47}$ in detail.

Here, we report results from photosynthetic gas exchange experiments under controlled conditions to quantify the effect of gas exchange on the isotopic composition of $\mathrm{CO}_{2}$. We investigated the effect on $\Delta_{47}$ of the residual $\mathrm{CO}_{2}(i)$ for different photosynthetic pathways $\left(\mathrm{C}_{3}\right.$ vs. $\mathrm{C}_{4}$ plants), $(\mathrm{ii})$ for two different values of leaf conductance in $\mathrm{C}_{3}$ plants, and (iii) for variations in light intensities for one $\mathrm{C}_{3}$ plant. This choice of plant species and gas exchange conditions enable us to directly test the proposed hypothesis proposed by Eiler and Schauble ${ }^{19}$ that $\mathrm{CO}_{2}-\mathrm{H}_{2} \mathrm{O}$ exchange and kinetic fractionation with back-diffusion of $\mathrm{CO}_{2}$ to the atmosphere are the main drivers controlling the $\Delta_{47}$ fractionation effect of photosynthetic gas exchange.

\section{Materials and methods}

Theory. Background. $\quad \Delta_{47}$ describes the deviation of the abundance of ${ }^{13} \mathrm{C}^{18} \mathrm{O}^{16} \mathrm{O}$ (the dominant isotopologue with nominal mass 47) from the random distribution of all isotopes across all isotopologues in a $\mathrm{CO}_{2}$ sample with the same bulk isotopic composition ${ }^{24}$. There are three isotopologues of $\mathrm{CO}_{2}$ with nominal mass of 47, ${ }^{13} \mathrm{C}^{18} \mathrm{O}^{16} \mathrm{O}\left(\right.$ abundance $\left.=46 \times 10^{-6}\right),{ }^{17} \mathrm{O}^{12} \mathrm{C}^{18} \mathrm{O}\left(\right.$ abundance $\left.=1.6 \times 10^{-6}\right)$ and ${ }^{17} \mathrm{O}^{13} \mathrm{C}^{17} \mathrm{O}\left(\right.$ abundance $\left.=1.6 \times 10^{-9}\right){ }^{19}$. The existing isotope ratio mass spectrometer instruments do not have sufficient mass resolving power to separate these isotopologues. Thus, the measured isotope ratio for nominal mass of 47 is a combination of these three isotopologues. Nevertheless, approximately $97 \%$ of the $\mathrm{CO}_{2}$ with nominal mass 47 is ${ }^{13} \mathrm{C}^{16} \mathrm{O}^{18} \mathrm{O}$ and the $\Delta_{47}$ value is mostly referred to as the value of ${ }^{13} \mathrm{C}^{16} \mathrm{O}^{18} \mathrm{O}$ isotopologue. $\Delta_{47}$ is calculated as ${ }^{19,35}$ :

$$
\Delta_{47}=\frac{{ }^{47} R}{{ }^{47} R^{*}}-1
$$

where $R$ stands for the measured ratio of a rare isotopologue of the indicated mass to the most abundant isotopologue, and $R^{*}$ is the isotopologue abundance ratio assuming that the heavy isotopes are distributed stochastically over all isotopologues ${ }^{19,24}$. In this case, ${ }^{47} R^{*}$ can be calculated from the isotopologues of mass 44 and 47 as ${ }^{47} R^{\star}=[47]{ }^{\star} /[44]^{\star}$ where $\left.[44]\right]^{*}=\left[{ }^{12} \mathrm{C}\right]\left[{ }^{16} \mathrm{O}\right]\left[{ }^{16} \mathrm{O}\right]$ and $47=2\left[{ }^{13} \mathrm{C}\right]\left[{ }^{16} \mathrm{O}\right]\left[{ }^{18} \mathrm{O}\right]+2\left[{ }^{12} \mathrm{C}\right]\left[{ }^{17} \mathrm{O}\right]\left[{ }^{18} \mathrm{O}\right]+\left[{ }^{13} \mathrm{C}\right]\left[{ }^{17} \mathrm{O}\right]\left[{ }^{17} \mathrm{O}\right]$. Note that the factor 2 is a symmetry number. This leads to

$$
{ }^{47} R^{*}=\frac{2\left[{ }^{13} \mathrm{C}\right]\left[{ }^{16} \mathrm{O}\right]\left[{ }^{18} \mathrm{O}\right]+\left[{ }^{13} \mathrm{C}\right]\left[{ }^{17} \mathrm{O}\right]\left[{ }^{17} \mathrm{O}\right]+2\left[{ }^{12} \mathrm{C}\right]\left[{ }^{17} \mathrm{O}\right]\left[{ }^{18} \mathrm{O}\right]}{\left[{ }^{12} \mathrm{C}\right]\left[{ }^{16} \mathrm{O}\right]\left[{ }^{16} \mathrm{O}\right]}=2{ }^{13} R^{18} R+2^{17} R^{18} R+{ }^{13} R\left({ }^{17} R\right)^{2}
$$

Measurements of both ${ }^{13} \mathrm{R}$ and ${ }^{18} \mathrm{R}\left(\operatorname{ratios}{ }^{13} \mathrm{C} /{ }^{12} \mathrm{C}\right.$ and ${ }^{18} \mathrm{O} /{ }^{16} \mathrm{O}$ ) require solving Eq. 3.

$$
-3 K^{2}\left({ }^{18} R\right)^{2 \lambda}+2 K^{45} R\left({ }^{18} R\right)^{\lambda}+2{ }^{18} R-{ }^{46} R=0
$$

where $K$ is ${ }^{17} \mathrm{R}_{\text {std }} /\left({ }^{18} \mathrm{R}_{\text {std }}\right){ }^{\lambda 36}$ and $\lambda$ is the three isotope exponent.

${ }^{13} R$ and ${ }^{18} R$ can be calculated from the corresponding $\delta$ values as $\left({ }^{13} R=\left(\delta^{13} \mathrm{CVPDB}_{\mathrm{VP}}+1\right) \times 0.011180\right.$, and $\left.{ }^{18} R=\left(\delta^{18} \mathrm{O}_{\text {VSMOW }}+1\right) \times 0.0020052\right)$. It is impossible to measure ${ }^{17} R$ of $\mathrm{CO}_{2}$ directly with traditional gas source isotope ratio mass spectrometry due to the isobaric interference of ${ }^{13} \mathrm{C}^{16} \mathrm{O}^{16} \mathrm{O}$ on ${ }^{12} \mathrm{C}^{17} \mathrm{O}{ }^{16} \mathrm{O}$. Variations in the isotope ratios ${ }^{18} \mathrm{R}$ and ${ }^{17} \mathrm{R}$ in a sample are closely linked in most common processes via the mass dependent fractionation equation $\left.\left[{ }^{18} R /{ }^{18} R_{\text {std }}\right]\right]^{\lambda}={ }^{17} R /{ }^{17} R_{\text {std }}$ where std stands for standard ${ }^{36}$. In this study, a value of 0.528 is 


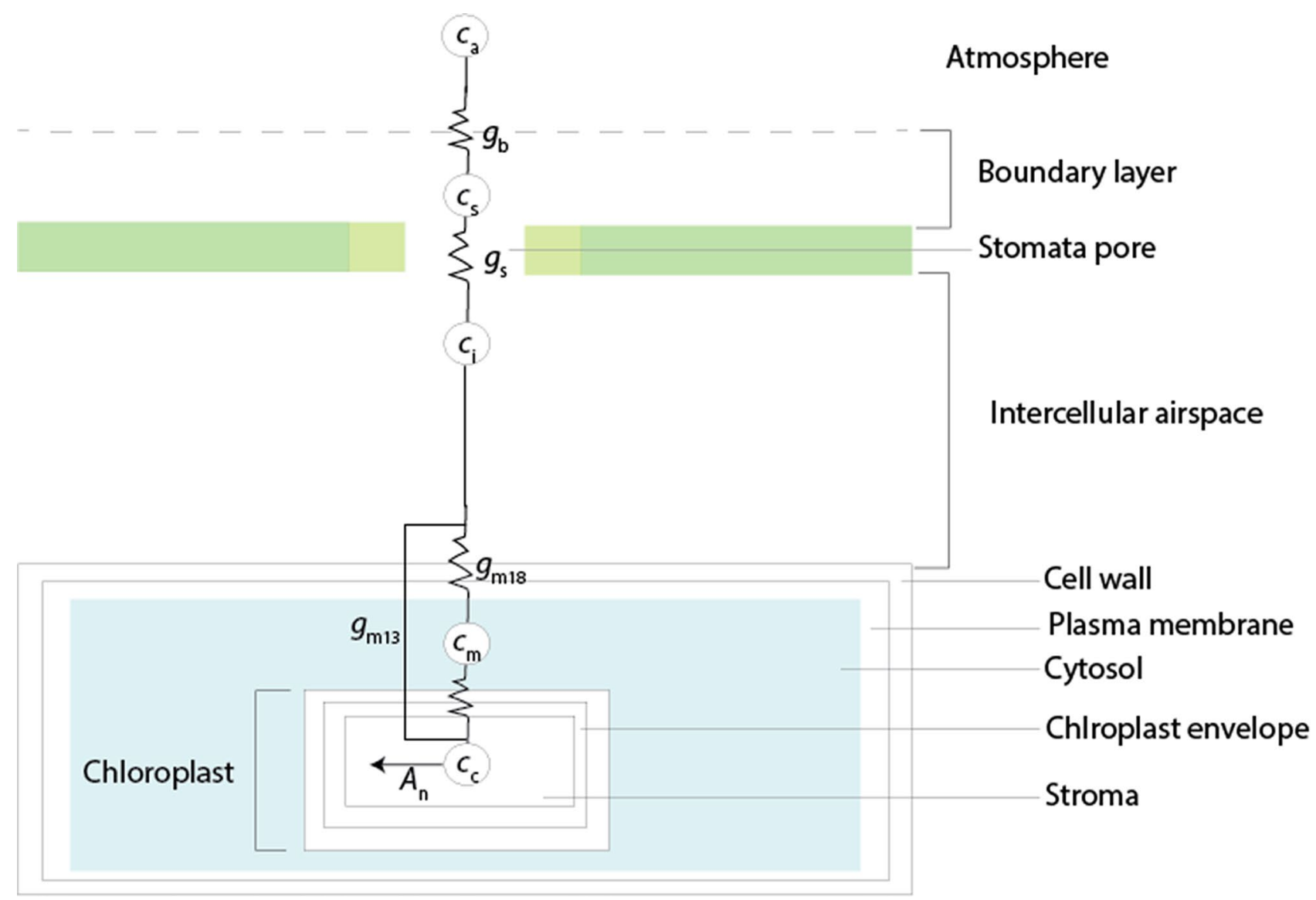

Figure 1. Schematic illustration of $\mathrm{CO}_{2}$ exchange fluxes, concentrations and conductivities during photosynthetic gas exchange. Net photosynthetic $\mathrm{CO}_{2}$ uptake in a leaf generates a concentration gradient over the leaf where $c_{\mathrm{a}}$ is the $\mathrm{CO}_{2}$ concentration of the air, $c_{\mathrm{s}}$ the $\mathrm{CO}_{2}$ concentration at the leaf surface, $c_{\mathrm{i}}$ is the $\mathrm{CO}_{2}$ concentration in the intercellular air space, $c_{\mathrm{m}}$ is the $\mathrm{CO}_{2}$ concentration in the mesophyll, i.e., the site of $\mathrm{CO}_{2}$ $\mathrm{H}_{2} \mathrm{O}$ exchange and $c_{\mathrm{c}}$ the $\mathrm{CO}_{2}$ concentration in the chloroplasts, the site of $\mathrm{CO}_{2}$ uptake. The $g_{\mathrm{b}}$ is the boundary layer conductance of $\mathrm{CO}_{2}$ from the atmosphere to the leaf surface, the stomatal conductance $g_{s}$ quantifies the gas exchange through the stomatal opening, $g_{\mathrm{m} 13}$ is the mesophyll conductance to the site of carbon uptake and $g_{\mathrm{m} 18}$ is the mesophyll conductance to the site of $\mathrm{CO}_{2}-\mathrm{H}_{2} \mathrm{O}$ exchange.

used as recommended by ${ }^{37,38} .{ }^{17} R$ was calculated as $\left({ }^{17} R=\left({ }^{18} \mathrm{R} / 0.0020052\right){ }^{0.528} \times 0.0003799\right)^{35,37,38}$. Recently, we have shown that ${ }^{17} \mathrm{R}$ can be measured independent of ${ }^{13} \mathrm{C}$ interference on $\mathrm{O}$ fragment ions $\mathrm{s}^{7}$.

$\delta^{13} \mathrm{C}$ and $\delta^{18} \mathrm{O}$ of the sample are calculated from $\delta^{45}$ and $\delta^{46}\left(\right.$ i.e. $\delta^{13} \mathrm{C}_{\mathrm{VPDB}} \cong \delta^{45}$ sample $+2 \times\left({ }^{17} \mathrm{R} /{ }^{13} \mathrm{R}\right)_{\mathrm{VPDB}-\mathrm{CO} 2}$ $\times\left(\delta^{45}\right.$ sample $-\lambda \times \delta^{45}$ sample $)$ and $\delta^{18} \mathrm{O}_{\mathrm{VPDB}-\mathrm{CO} 2} \cong\left[\delta^{46}\right.$ sample $\left.\left.-0.0021 \times \delta^{13} \mathrm{C}_{\mathrm{VPDB}}\right] / 0.99904\right)$, where ${ }^{17} R /{ }^{13} R$ is $0.03516^{37}$. The $\delta$ value is calculated as follow:

$$
\delta^{\mathrm{x}}=\left(\frac{{ }^{\mathrm{x}} \mathrm{R}_{\text {sample }}}{{ }^{\mathrm{x}} \mathrm{R}_{\text {standard }}}-1\right)
$$

where $x$ can be $13,18,45,46$ and 47 (for ${ }^{13} \mathrm{C},{ }^{18} \mathrm{O},{ }^{13} \mathrm{C}^{16} \mathrm{O}^{16} \mathrm{O},{ }^{12} \mathrm{C}^{16} \mathrm{O}^{18} \mathrm{O}$ and ${ }^{13} \mathrm{C}^{16} \mathrm{O}{ }^{18} \mathrm{O}$, respectively).

$\mathrm{CO}_{2}$ exchange fluxes during photosynthesis. The $\mathrm{CO}_{2}$ uptake by $\mathrm{C}_{3}$ plants is schematically illustrated in Fig. 1. Net photosynthetic $\mathrm{CO}_{2}$ uptake in a leaf generates a concentration gradient from the atmosphere $\left(c_{\mathrm{a}}\right)$ to the boundary layer $\left(c_{\mathrm{s}}\right)$, intercellular airspace $\left(c_{\mathrm{i}}\right)$, the mesophyll cell $\left(c_{\mathrm{m}}\right)$ and the chloroplast $\left(c_{\mathrm{c}}\right)$, where $\mathrm{CO}_{2}$ is fixed (in $\mathrm{C}_{3}$ plants) (see Fig. 1) ${ }^{39-42}$. In the chloroplast, the enzyme RubisCO catalyzes the conversion of carbon dioxide to the three-carbon acid 3-phosphoglyceric acid (3PGA). $c_{\mathrm{c}}$ determines the availability of $\mathrm{CO}_{2}$ for carboxylation, which is the rate-limiting substrate. The concentration gradient between $c_{\mathrm{a}}$ and $c_{\mathrm{c}}$ drives the diffusion of $\mathrm{CO}_{2}$ into the leaf. The diffusion process can be described mathematically following Fick's law of diffusion as:

$$
A_{\mathrm{n}}=g_{\mathrm{L}}\left(c_{\mathrm{a}}-c_{\mathrm{c}}\right)
$$

where $g_{\mathrm{L}}$ is the total conductance (inverse of resistance, $1 / r_{\mathrm{L}}$ ) of the leaf for $\mathrm{CO}_{2}$ diffusion. Total $g_{\mathrm{L}}$ is conveniently subdivided into three parts that act in series. The boundary layer conductance $\left(g_{\mathrm{b}}\right)$ represents the conductance through a thin layer of near-stagnant air surrounding the leaf; it is a function of air turbulence and leaf area. The stomatal conductance $\left(g_{s}\right)$ varies with the opening and frequency of the stomata. The mesophyll conductance 
$\left(g_{\mathrm{m}}\right)$ quantifies the conductance for transport of $\mathrm{CO}_{2}$ from the intercellular air space in the leaf to the site of $\mathrm{CO}_{2}-\mathrm{H}_{2} \mathrm{O}$ exchange in the mesophyll or the carboxylation in the chloroplast. The latter is expressed as $g_{\mathrm{m} 13}$ and the former is denoted as $g_{\mathrm{m} 18}$, which refers to estimation using $\delta^{13} \mathrm{C}$ and $\delta^{18} \mathrm{O}$ respectively (see Sect. "Mesophyll conductance"). A small part of this transport occurs in the gas phase through a residual part of the intercellular air space. The major transport pathway is in the liquid phase, through the wall of the mesophyll cell, the plasmalemma and further into the cell to the site of oxygen exchange between $\mathrm{CO}_{2}$ and $\mathrm{H}_{2} \mathrm{O}$ that is catalyzed by carbonic anhydrase (CA). $\mathrm{CO}_{2}$ diffuses further through the chloroplast envelope and into the chloroplast where carboxylation occurs ${ }^{39,40,43}$.

Mesophyll conductance. For $\mathrm{C}_{3}$ plants, we used the discrimination against ${ }^{13} \mathrm{C}\left(\Delta_{\mathrm{A}}{ }^{13} \mathrm{C}\right)$ (Eq. 6) to estimate the mesophyll conductance $\left(g_{m 13}\right)$ from the intercellular airspace to the carboxylation site (Eq. 7) as described in $^{44}$. The overall isotope fractionation associated with photosynthetic gas exchange is referred to as discrimination, which quantifies the enrichment or depletion of the isotope composition of $\mathrm{CO}_{2}$ in the surrounding atmosphere relative to the $\mathrm{CO}_{2}$ assimilated, see Eq. $(6)^{42,45,46}$. Experimentally, the discrimination $\left(\Delta_{\mathrm{A}}\right)$ is calculated from the isotopic composition and mole fraction of $\mathrm{CO}_{2}$ entering and leaving the cuvette ${ }^{47-49}$, as shown in Eq. (6).

$$
\Delta_{\text {Aobs }}^{\mathrm{x}}=\frac{\zeta\left(\delta_{\mathrm{a}}^{\mathrm{x}}-\delta_{\mathrm{e}}^{\mathrm{x}}\right)}{1+\delta_{\mathrm{a}}^{\mathrm{x}}-\zeta\left(\delta_{\mathrm{a}}^{\mathrm{x}}-\delta_{\mathrm{e}}^{\mathrm{x}}\right)}
$$

where $x$ is either 13,18 or 47 (for ${ }^{13} \mathrm{C},{ }^{18} \mathrm{O}$ and ${ }^{13} \mathrm{C}^{18} \mathrm{O}{ }^{16} \mathrm{O}$ isotope composition, respectively), $\zeta=c_{e} /\left(c_{e}-c_{a}\right)$ and $c$ is the mole fraction of the $\mathrm{CO}_{2}$ entering (index $e$ ) and leaving (index a) the cuvette.

$g_{m 13}$ is calculated from the difference between the observed ${ }^{13} \mathrm{C}$ discrimination $\left(\Delta_{\mathrm{A}}{ }^{13} \mathrm{C}_{\mathrm{obs}}\right)$ and the discrimination at infinite $g_{\mathrm{m}}\left(c_{\mathrm{i}}=\mathrm{c}_{\mathrm{c}}\right)$ as:

$$
g_{m 13}=\frac{A_{n} / P}{c_{i}-c_{c}}=\left(\frac{1+t^{13}}{1-t^{13}}\right)\left(\frac{A_{n}\left(b-a_{m}-\frac{\alpha_{b}}{\alpha_{e} \alpha_{R}} e^{\prime} \frac{R_{D}}{A_{n}}\right)}{\left(\Delta_{A}^{13} C_{i}-\Delta_{A}^{13} C_{o b s}\right) P c_{a}}\right)
$$

where $P$ is the ambient pressure, $t^{13}$ is a ternary correction factor for ${ }^{13} \mathrm{CO}_{2}, b$ the fractionation due to uptake by Rubisco, and $a_{\mathrm{m}}$ the combination of the fractionations associated with ${ }^{13} \mathrm{CO}_{2}$ dissolution and diffusion through water, respectively. $e^{\prime}, R_{\mathrm{D}}, \alpha_{e}$, and $\alpha_{b}$ are the fractionation factor for mitochondrial respiration including the apparent fractionation, the day respiration rate (mitochondrial respiration in the light) the fractionation factor for day respiration with respect to net assimilation and the fractionation factor for $\mathrm{C}_{3}$ carboxylation, respectively. $\alpha_{R}=1+\left(\mathrm{R}_{\mathrm{D}} / \mathrm{A}_{\mathrm{n}}\right) \times\left(e^{\prime} / \alpha_{e}\right)$. A detailed description of the equations, used parameters and definitions of fractionation factors is provided in Table $\mathrm{S} 1$ of the supplementary material.

In $\mathrm{C}_{4}$ plants, the $\mathrm{CO}_{2}$ is converted to bicarbonate and fixed to a four-carbon acid catalyzed by phosphoenol pyruvate carboxylase (PEPC) in the mesophyll. Unlike for $\mathrm{C}_{3}$ plants, it is impossible to estimate mesophyll conductance from $\Delta_{\mathrm{A}}{ }^{13} \mathrm{C}$ for $\mathrm{C}_{4}$ plants due to the low photosynthetic fractionation ${ }^{50,51}$. However, the apparent discrimination against ${ }^{18} \mathrm{O}\left(\Delta_{\mathrm{A}}{ }^{18} \mathrm{O}\right)$ can be used to estimate the mesophyll conductance from the intercellular air space to the site of $\mathrm{CO}_{2}-\mathrm{H}_{2} \mathrm{O}$ isotope equilibration, $g_{m 18}$, as described in ${ }^{41,47,52-54}$, for both $\mathrm{C}_{3}$ and $\mathrm{C}_{4}$ plants. The analytical expression for estimating $g_{m 18}$ (Eq. 8) assumes that the degree of equilibration between $\mathrm{CO}_{2}$ and $\mathrm{H}_{2} \mathrm{O}$ is $100 \%$. Some studies have reported that the degree of equilibration can be lower than $100 \%$, especially for $\mathrm{C}_{4}$ plants, which have a lower CA activity ${ }^{29,31,47,54}$. Detailed information is provided in Table S1 of the supplementary material.

$$
\mathrm{g}_{\mathrm{m} 18}=\frac{\mathrm{A}_{\mathrm{n}} / \mathrm{P}}{\mathrm{c}_{\mathrm{i}}-\mathrm{c}_{\mathrm{m}}}=\left(\frac{\mathrm{A}_{\mathrm{n}} / \mathrm{P}}{\mathrm{c}_{\mathrm{i}}}\right) \frac{\delta^{18} \mathrm{O}_{\mathrm{A}} \alpha_{18 \mathrm{w}}+\mathrm{a}_{18 \mathrm{w}}-\delta^{18} \mathrm{O}_{\mathrm{m}}}{\delta^{18} \mathrm{O}_{\mathrm{i}}-\delta^{18} \mathrm{O}_{\mathrm{m}}}
$$

$\delta^{18} \mathrm{O}_{\mathrm{i}}$ is $\delta^{18} \mathrm{O}$ of $\mathrm{CO}_{2}$ in the intercellular airspace, $\alpha_{18 w}$ is the fractionation factor for ${ }^{12} \mathrm{C}^{18} \mathrm{O}^{16} \mathrm{O}$ during diffusion and dissolution in water, $a_{18 w}$ is the discrimination against ${ }^{12} \mathrm{C}^{18} \mathrm{O}^{16} \mathrm{O}$ during diffusion and dissolution in water, $a_{18 w}=\alpha_{18 w}-1, \delta^{18} \mathrm{O}_{\mathrm{A}}$ is $\delta^{18} \mathrm{O}$ of the assimilated $\mathrm{CO}_{2}$ and $\delta^{18} \mathrm{O}_{\mathrm{m}}$ is the $\delta^{18} \mathrm{O}$ of $\mathrm{CO}_{2}$ in equilibrium with leaf water at the $\mathrm{CO}_{2}-\mathrm{H}_{2} \mathrm{O}$ exchange site. In previous studies, the difference between $\delta^{18} \mathrm{O}$ of bulk leaf water and the water at the evaporation site was about 1 to $2 \%$ higher $^{13,54}$, but larger differences have also been reported ${ }^{55}$. In this study, we assumed that the $\delta^{18} \mathrm{O}$ of leaf water at the $\mathrm{CO}_{2}-\mathrm{H}_{2} \mathrm{O}$ exchange site is enriched by $2 \%$ compared to bulk leaf water and the degree of equilibration between $\mathrm{CO}_{2}$ and leaf water is $100 \%$.

Photosynthetic $\Delta_{47}$ discrimination. The effect of photosynthetic gas exchange on $\Delta_{47}$ depends on the assimilation rate, the various conductances mentioned before and the fraction of $\mathrm{CO}_{2}$ that diffuses back to the atmosphere after isotope exchange with leaf water. For a laminar boundary layer, diffusion through the boundary layer decreases the $\Delta_{47}$ value of residual $\mathrm{CO}_{2}$ by an amount equal to the boundary layer diffusive fractionation $(+0.2$ $\%$ ) multiplied by the fraction of $\mathrm{CO}_{2}$ enters leaves and is fixed $(\sim 1 / 3)$, i.e., $0.07 \%$. In this study, we used a fan (see Sect. "Leaf cuvette set-up"), which creates a turbulent boundary layer with an estimated conductance of $5 \mathrm{~mol} \mathrm{~m}^{-2} \mathrm{~s}^{-1}$. The boundary layer conductance for the leaf cuvette was determined using wet filter paper from measurements of relative humidity and temperature of air in the cuvette as described in Parkinson ${ }^{56}$. As a result, the fractionation in $\Delta_{47}$ due to diffusion through the boundary layer is negligible compared to the precision of the measurement (ca. $0.002 \%$ ). Figure 2 illustrates the effect of photosynthetic gas exchange on $\Delta_{47}$ for two extreme scenarios. The first "uptake dominated" scenario assumes that all the $\mathrm{CO}_{2}$ entering stomata gets assimilated, leading to $c_{\mathrm{m}} / c_{\mathrm{a}} \sim 0$ whereas in the second "exchange dominated" scenario all $\mathrm{CO}_{2}$ diffuses back to the atmosphere after exchange with the leaf water leading to $c_{\mathrm{m}} / c_{\mathrm{a}} \sim 1$. In the uptake dominated scenario, the result- 


\section{Uptake dominated}

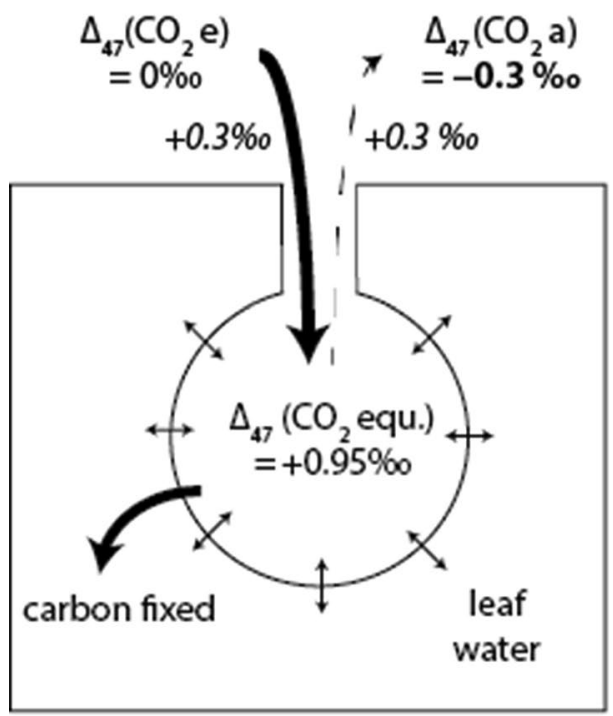

\section{Exchange dominated}

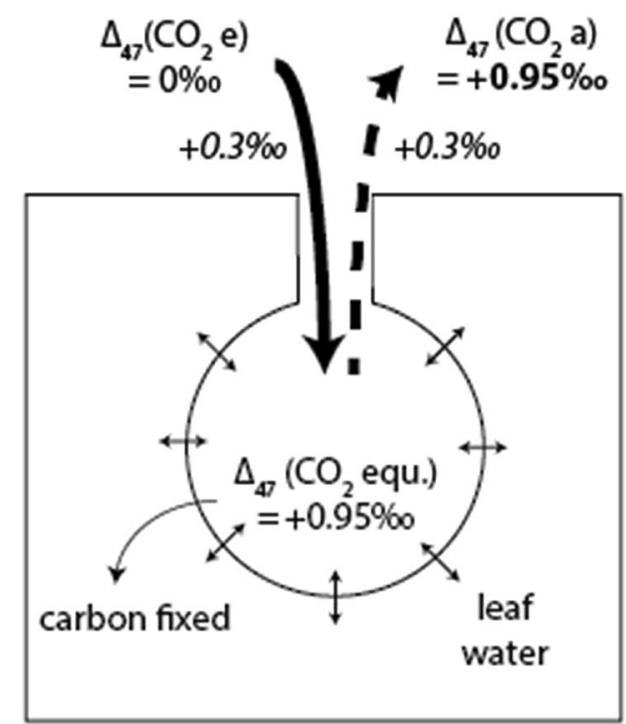

Figure 2. Schematic illustration of the clumped isotope fractionation during air-leaf gas exchange. $\Delta_{47}$ of the $\mathrm{CO}_{2}$ in the air surrounding the leaf is mainly controlled by $\mathrm{CO}_{2}-\mathrm{H}_{2} \mathrm{O}$ exchange and kinetic fractionation during diffusion into and out of the leaf stomata. In the uptake dominated case $\left(c_{\mathrm{m}} / c_{\mathrm{a}} \sim 0\right),-0.3 \%$ comes from the fact that diffusion mediated leaf air interaction will reduce the $\Delta_{47}$ value by $0.3 \%$, neglecting other effects. Diffusion only will reduce the $\Delta_{47}$ value by $0.3 \%$ multiplied by the fraction of $\mathrm{CO}_{2}$ entering the leaf that is assimilated ${ }^{19}$. The boundary layer conductance is large and we have omitted it here.

ing $\Delta_{47}$ signal is mainly affected by diffusion, in the exchange dominated scenario the $\Delta_{47}$ signal is dominated by the $\mathrm{CO}_{2}-\mathrm{H}_{2} \mathrm{O}$ exchange. A similar scheme for $\delta^{18} \mathrm{O}$ is shown in Figure $\mathrm{S} 2$ of the supplementary material.

The fractionation of $\Delta_{47}$ associated with photosynthetic gas exchange $\left(\Delta_{\mathrm{A}} \Delta_{47 \mathrm{obs}}\right)$ was calculated in a similar way as $\Delta_{\text {Aobs }}^{x}$ in Eq. (6) from the difference in $\mathrm{CO}_{2}$ concentration and isotopic composition between the air entering and leaving the leaf cuvette (Eq. 9). For mixing of two different populations of $\mathrm{CO}_{2}, \Delta_{47}$ is not a conserved quantity and the error introduced by adding or subtracting $\Delta_{47}$ values linearly depends on the relative difference in the $\delta^{18} \mathrm{O}$ and $\delta^{13} \mathrm{C}$ of the two gases ${ }^{19,20,57,58}$. In our study, the maximum difference between the $\delta^{18} \mathrm{O}$ and $\delta^{13} \mathrm{C}$ value of the $\mathrm{CO}_{2}$ entering and leaving the cuvette is $14 \%$ and $4 \%$, respectively. For this rather small range, the error introduced due to linear addition and subtraction of $\Delta_{47}$ values of the $\mathrm{CO}_{2}$ entering and leaving the cuvette is not significant $(<0.01 \%)$.

$$
\Delta_{\mathrm{A}} \Delta_{47 \mathrm{obs}}=\frac{\zeta\left(\Delta_{47 \mathrm{a}}-\Delta_{47 \mathrm{e}}\right)}{1+\Delta_{47 \mathrm{a}}-\zeta\left(\Delta_{47 \mathrm{a}}-\Delta_{47 \mathrm{e}}\right)}
$$

Leaf cuvette model. To explore the effects of conductance, assimilation rate and back-diffusion of $\mathrm{CO}_{2}$ to the atmosphere on the $\Delta_{47}$ of ambient $\mathrm{CO}_{2}$ in detail we used a leaf cuvette model [https://git.wur.nl/leaf-model] ${ }^{59}$ that has been used for the interpretation of $\Delta^{17} \mathrm{O}$ measurements in leaf exchange experiments recently ${ }^{13}$. In the model we assumed that $\mathrm{CO}_{2}-\mathrm{H}_{2} \mathrm{O}$ exchange in the mesophyll is rapid enough to constantly set $\Delta_{47}$ to thermodynamic equilibrium with the water, i.e., $\Delta_{47}=0.95 \%$ at $20{ }^{\circ} \mathrm{C}^{25}$. Thus, any change in bulk isotopic composition of $\mathrm{CO}_{2}$ due to assimilation does not affect $\Delta_{47}{ }^{19}$. Furthermore, $\mathrm{CO}_{2}$ diffusion into and out of the intercellular air space through the stomata is associated with a fractionation constant of $+0.3 \%$ for $\Delta_{47}{ }^{19}$ whereas $\mathrm{CO}_{2}$ diffusion through the boundary layer has a fractionation constant of $+0.2 \%$ for $\Delta_{47}$.

The steady state model considers five compartments: (i) atmosphere (air in the leaf surrounding), (ii) the leaf surface, (iii) the intercellular airspace of the leaf, (iv) the mesophyll cell of the leaf, and (v) the chloroplast (see Fig. 1). The air enters the leaf cuvette at a flow rate $F_{\mathrm{e}}$ and a $\mathrm{CO}_{2}$ concentration $c_{\mathrm{e}}$ with a well-defined isotopic composition $\delta_{\mathrm{e}}$ (where $\delta$ can stand for $\delta^{13} \mathrm{C}, \delta^{18} \mathrm{O}, \delta^{47}$ and $\Delta_{47}$, see Sect. "Background" for definition). The leaf inside the cuvette takes up a portion of the $\mathrm{CO}_{2}$ and this uptake is associated with an isotope fractionation. The air flowing out of the cuvette has flow rate $F_{\mathrm{a}}, \mathrm{CO}_{2}$ concentration $c_{\mathrm{a}}$ and isotopic composition $\delta_{\mathrm{a}}$. The photosynthetic uptake in the chloroplasts leads to a concentration gradient between the air surrounding the leaf and the chloroplasts so that there is a net flow of $\mathrm{CO}_{2}$ from the cuvette into the intercellular airspace, to the mesophyll cell, and finally to the chloroplasts. The corresponding $\mathrm{CO}_{2}$ concentrations decrease accordingly in the order $c_{\mathrm{a}}$, $c_{\mathrm{s}}, c_{\mathrm{i}}, c_{\mathrm{m}}$ and $c_{\mathrm{c}}$. Diffusion, isotopic equilibration with $\mathrm{H}_{2} \mathrm{O}, \mathrm{CO}_{2}$ uptake and mixing between the model reservoirs lead to a change in isotopic composition $\left(\delta_{\mathrm{a}}, \delta_{\mathrm{s}}, \delta_{\mathrm{i}}, \delta_{\mathrm{m}}\right.$ and $\left.\delta_{\mathrm{c}}\right)$. The magnitude of the exchange fluxes between the 


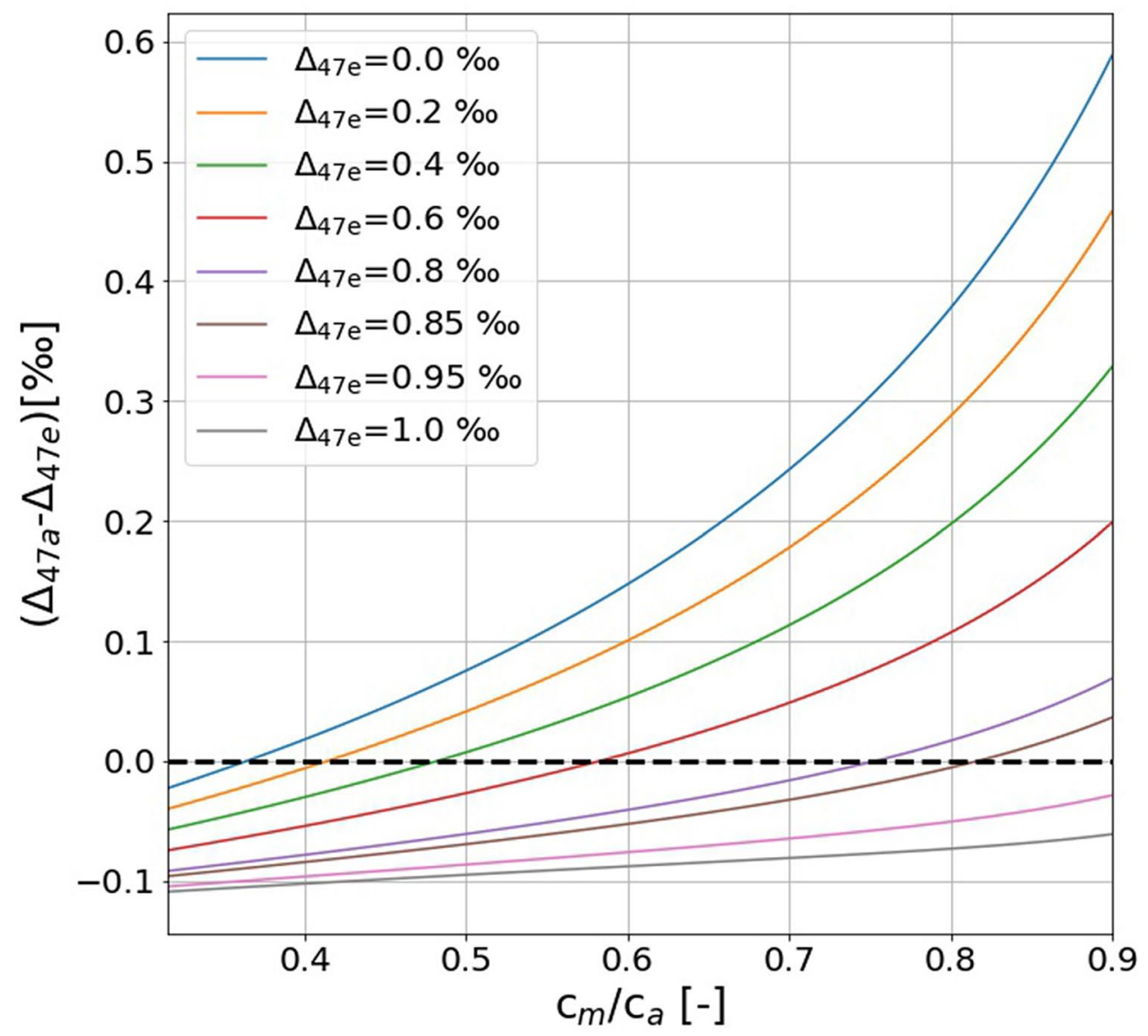

Figure 3. Difference between $\Delta_{47}$ of out- and inflowing $\mathrm{CO}_{2}$ as function of the fraction of $\mathrm{CO}_{2}$ diffusing back to the atmosphere $\left(c_{\mathrm{m}} / c_{\mathrm{a}}\right)$ calculated with the leaf cuvette model. The black dashed line shows the $c_{\mathrm{m}} / c_{\mathrm{a}}$ ratio where the $\Delta_{47}$ relative difference between the ingoing and outgoing $\mathrm{CO}_{2}$ becomes zero for the corresponding $\Delta_{47}$ of $\mathrm{CO}_{2}$ entering the cuvette.

compartments is defined by the boundary layer conductance $g_{\mathrm{b}}$, stomatal conductance $g_{\mathrm{s}}$ and the mesophyll conductances $g_{\mathrm{m} 18}$ and $g_{\mathrm{m} 13}$. In the leaf cuvette model, the boundary layer conductance $g_{\mathrm{b}}$ is assumed $5 \mathrm{~mol} \mathrm{~m}^{-2} \mathrm{~s}^{-1}$, similar to the value determined in the experiment.

Figure 3 shows how the $\Delta_{47}$ value changes between incoming and outgoing $\mathrm{CO}_{2}$ in the leaf cuvette model for $c_{\mathrm{m}} / c_{\mathrm{a}}$ ratios ranging from 0.3 to 0.9 and $\Delta_{47}$ values of the entering $\mathrm{CO}_{2}$ between $0.0 \%$ and $1.0 \%$. It is evident that the relative changes are small when $\Delta_{47}$ of the incoming $\mathrm{CO}_{2}$ is close to the equilibrium value $(0.9-1.0 \%)$ at ambient temperatures. The changes are much larger if the $\Delta_{47}$ of the incoming $\mathrm{CO}_{2}$ is close to a random distribution $\left(\Delta_{47}=0.0 \%\right.$ ). This motivated us to carry out the gas exchange experiments with isotopically 'scrambled' (i.e., $\Delta_{47}$ close to zero) $\mathrm{CO}_{2}$ (see below).

Plant material and growth conditions. Three plant species were used for the experiments, belonging to different functional groups: Sunflower (Helianthus annuus L. cv, Giganteus), Atlantic ivy [Hedera hybernica (Kirchner) Bean (syn. Hedera helix var. hibernica)], and maize (Zea mays L. cv, Torres). The fast-growing annual $\mathrm{C}_{3}$ species Helianthus is characterized by short-lived leaves with high photosynthetic capacity and conductance for $\mathrm{CO}_{2}$ diffusion. The other $\mathrm{C}_{3}$ species, the evergreen Hedera, has long-lived leaves with a lower photosynthetic capacity and conductance. The third species, $\mathrm{Zea}$, has $\mathrm{C}_{4}$ metabolism, a high photosynthetic capacity and low conductance.

Helianthus and Zea were grown from seed in a growth room at $20^{\circ} \mathrm{C}$, a relative humidity of $70 \%$ and a photosynthetic photon flux density (PPFD) of $250 \mu \mathrm{mol} \mathrm{m} \mathrm{m}^{-2} \mathrm{~s}^{-1}$ for a day length of $16 \mathrm{~h}$. The first pair of two leaves of Helianthus was used for the experiments when fully grown at three to four weeks after planting. Younger leaves that shaded them were removed. For Zea mays, a section of the fifth or sixth leaf at about two thirds of total leaf length was used at a plant age of around 7 weeks. These leaves were about $5 \mathrm{~cm}$ wide, giving a sufficiently large leaf area in the cuvette. Hedera plants were obtained from a grower, pruned to reduce self-shading and further grown in the experimental garden in full daylight. They were used for the experiments in early November 2015 when outside average maximum day temperature during the preceding month was $14{ }^{\circ} \mathrm{C}$. Mature leaves that could be accommodated intact in the cuvette were used for the experiments. For all the experiments, leaves 


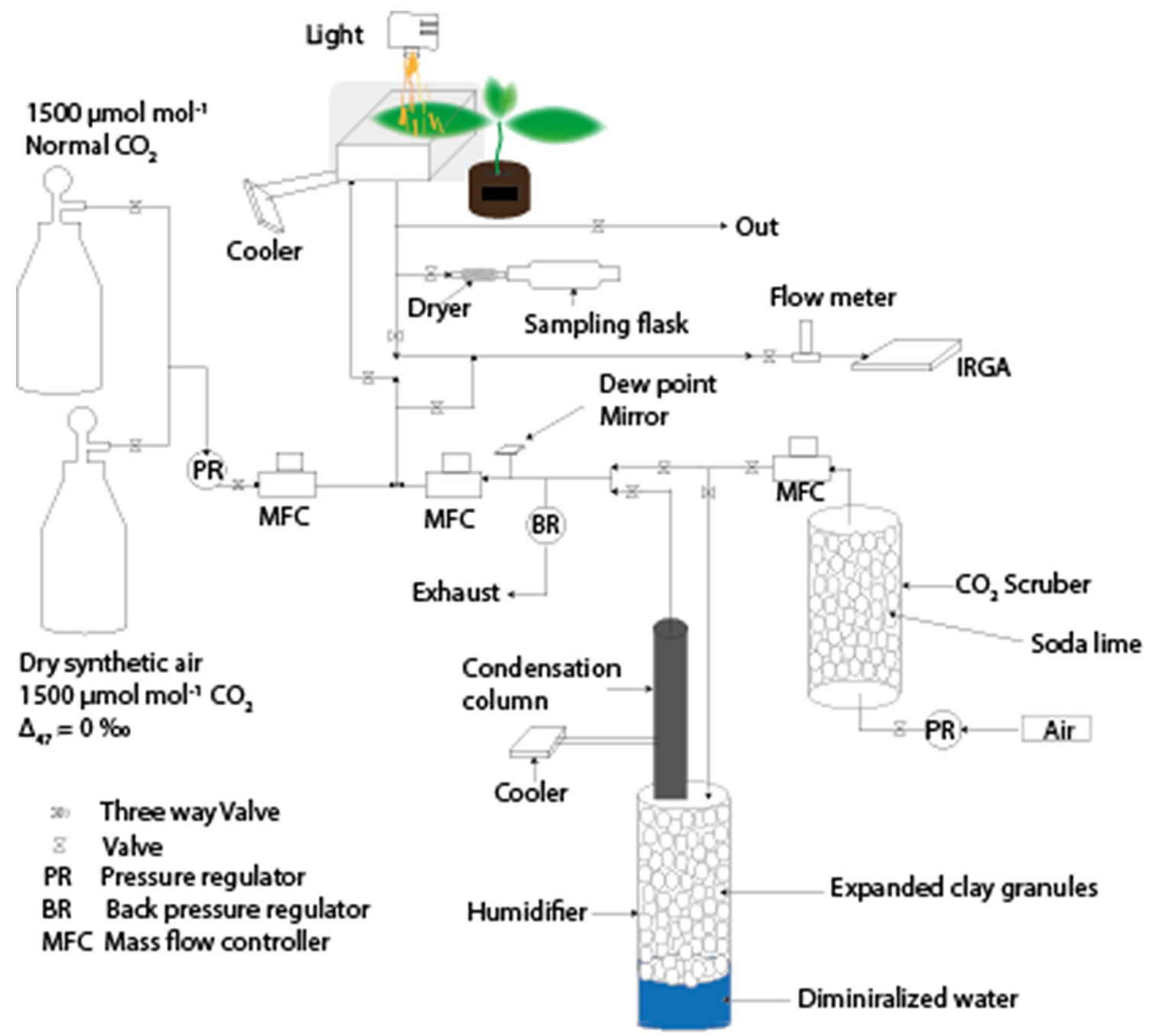

Figure 4. Leaf chamber set-up, modified from Adnew et al. $(2020)^{13}$. A single leaf was placed in the leaf cuvette and the light intensity could be regulated to manipulate the assimilation rate. A gas-mixing unit was used to mix dry synthetic air with scrambled $\mathrm{CO}_{2}$ with humidified $\mathrm{CO}_{2}$-free air to obtain an overall $\mathrm{CO}_{2}$ concentration of the ingoing air of $500 \mu \mathrm{mol} \mathrm{mol}{ }^{-1}$. The flow rate was adjusted to the photosynthetic activity of the leaf to obtain a $\mathrm{CO}_{2}$ concentration of about $400 \mu \mathrm{mol} \mathrm{mol}^{-1}$ at the outlet $\left(0.6\right.$ to $\left.1.5 \mathrm{~L} \mathrm{~min}^{-1}\right) . \mathrm{CO}_{2}$ and $\mathrm{H}_{2} \mathrm{O}$ concentrations were monitored with an infrared gas analyzer (IRGA). Once steady state was reached, the outgoing air was sampled in one $2 \mathrm{~L}$ and one $1 \mathrm{~L}$ glass flasks, in series. The bulk isotope composition $\left(\delta^{13} \mathrm{C}\right.$ and $\left.\delta^{18} \mathrm{O}\right)$ of the normal $\mathrm{CO}_{2}$ and scrambled $\mathrm{CO}_{2}$ are identical.

remained attached to the plants during the experiments. Both Helianthus and Zea are watered from tap water whereas Hedera received largely rain water.

Leaf cuvette set-up. The isotopic effect of $\mathrm{CO}_{2}$ exchange during photosynthesis was investigated with an open gas exchange measurement system similar to the one described by ${ }^{13,60}$ (Fig. 4). A controlled flow of air entered and left the leaf cuvette, which had a $7 \times 7 \mathrm{~cm}$ transparent window on top that limited the maximum width of the leaves that could be accommodated. A fan inside the leaf cuvette increased boundary layer conductance to around $5 \mathrm{~mol} \mathrm{~m}^{-2} \mathrm{~s}^{-1}$ and mixed the air thoroughly so that the air leaving the cuvette was a representative sample of the air inside. The chamber was illuminated from above by a halogen lamp that allowed control of the PPFD incident on the leaf. Leaf temperature was measured with thermocouples appressed to the abaxial side of the leaf. Water at $20^{\circ} \mathrm{C}$ was circulated through the double wall of the cuvette, which stabilized leaf temperature up to $3{ }^{\circ} \mathrm{C}$ higher depending on PPFD and transpiration rate (Table 1 ).

A gas-mixing unit made from $1 / 4$ inch stainless-steel tubing was attached to the inlet port of the cuvette. Synthetic dry air with a $\mathrm{CO}_{2}$ concentration of about $1500 \mu \mathrm{mol} \mathrm{mol}{ }^{-1}$ was mixed with $\mathrm{CO}_{2}$-free air of controlled humidity to set the $\mathrm{CO}_{2}$ concentration of inlet air to $500 \mu \mathrm{mol} \mathrm{mol}^{-1}$. Air flows were controlled with flow controllers. Two of these mixing units were used, one with untreated $\mathrm{CO}_{2}$ and the other one with the same $\mathrm{CO}_{2}$ that was previously isotopically scrambled at $1000^{\circ} \mathrm{C}$ (target $\Delta_{47} \sim 0.0 \%$, see below for discussion of deviations). The air flow rate was adjusted so that the $\mathrm{CO}_{2}$ concentration at the outlet (and thus also in the cuvette) was about 


\begin{tabular}{|c|c|c|c|c|c|c|c|c|c|c|c|c|c|c|c|}
\hline Species & \begin{tabular}{|l|}
$\begin{array}{l}\text { Leaf } \\
\text { type }\end{array}$ \\
\end{tabular} & {$\left[\begin{array}{l}\text { PPFD } \\
\frac{\mu m o l}{m^{2} s}\end{array}\right]$} & $\begin{array}{l}\text { No. } \\
\text { exp }\end{array}$ & $T_{\text {leaf }}\left[{ }^{\circ} \mathrm{C}\right]$ & {$\left[\frac{\mathrm{e}^{\mathrm{\mu}} \mathrm{\mu mol}}{\mathrm{mol}}\right]$} & 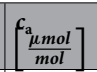 & $A_{\mathrm{n}}\left[\frac{\mu m o l}{m^{2} s}\right]$ & $E\left[\frac{m m o l}{m^{2} s}\right]$ & $g_{\mathrm{s}}\left[\frac{m o l}{m^{2} s}\right]$ & $g_{\mathrm{g} 13} \frac{m_{\text {mol }}}{m^{2} s \text { bar }}$ & $\mid \frac{g_{\mathrm{m} 18}}{\mathrm{~m}^{2} \mathrm{~s} \text { bar }}$ & $c_{\mathrm{i}} / c_{\mathrm{a}}$ & $c_{\mathrm{c}} / c_{\mathrm{a}}$ & $c_{m} / c_{a}$ & $\delta^{18} \mathrm{O}_{\mathrm{LW}}$ \\
\hline \multirow{13}{*}{$\begin{array}{l}\text { H.ann- } \\
\text { uus }\end{array}$} & \multirow{13}{*}{$\mathrm{C}_{3}$} & 200 & $(1)$ & 21.4 & 499 & 420 & 12.0 & 2.3 & 0.27 & $0.33 \pm 0.05$ & $0.59 \pm 0.05$ & 0.80 & $0.71 \pm 0.02$ & $0.75 \pm 0.01$ & $4.3 \pm 0.1$ \\
\hline & & & (2) & 21.2 & 499 & 406 & 12.2 & 2.6 & 0.32 & $0.17 \pm 0.05$ & $0.82 \pm 0.05$ & 0.81 & $0.64 \pm 0.02$ & $0.78 \pm 0.03$ & $6.0 \pm 0.1$ \\
\hline & & & (3) & 20.6 & 501 & 409 & 11.3 & 2.1 & 0.35 & $0.36 \pm 0.05$ & $0.64 \pm 0.05$ & 0.85 & $0.78 \pm 0.02$ & $0.81 \pm 0.01$ & $6.5 \pm 0.1$ \\
\hline & & \multicolumn{2}{|c|}{ Mean \pm SD } & $21.1 \pm 0.4$ & $500 \pm 1$ & $412 \pm 7$ & $11.8 \pm 0.5$ & $2.3 \pm 0.3$ & $0.31 \pm 0.04$ & $0.27 \pm 0.1$ & $0.68 \pm 0.12$ & $0.82 \pm 0.03$ & $0.71 \pm 0.07$ & $0.78 \pm 0.03$ & $5.6 \pm 1.2$ \\
\hline & & 700 & $(4)$ & 21.8 & 500 & 399 & 24.4 & 4.1 & 0.51 & $0.61 \pm 0.05$ & $0.93 \pm 0.05$ & 0.78 & $0.68 \pm 0.02$ & $0.71 \pm 0.01$ & $4.7 \pm 0.1$ \\
\hline & & & (5) & 22.2 & 499 & 406 & 20.9 & 3.0 & 0.33 & $0.46 \pm 0.05$ & $0.67 \pm 0.05$ & 0.74 & $0.63 \pm 0.02$ & $0.66 \pm 0.01$ & $6.1 \pm 0.1$ \\
\hline & & & (6) & 21.3 & 500 & 404 & 20.8 & 3.5 & 0.45 & $0.43 \pm 0.05$ & $0.52 \pm 0.05$ & 0.79 & $0.67 \pm 0.02$ & $0.69 \pm 0.01$ & $6.6 \pm 0.1$ \\
\hline & & & (7) & 21.4 & 499 & 405 & 20.7 & 3.7 & 0.45 & $0.65 \pm 0.05$ & $0.72 \pm 0.05$ & 0.79 & $0.71 \pm 0.02$ & $0.72 \pm 0.01$ & $6.5 \pm 0.1$ \\
\hline & & \multicolumn{2}{|c|}{ Mean \pm SD } & $21.7 \pm 0.4$ & $500 \pm 1$ & $404 \pm 3$ & $21.7 \pm 1.8$ & $3.6 \pm 0.5$ & $0.44 \pm 0.08$ & $0.54 \pm 0.1$ & $0.71 \pm 0.17$ & $0.78 \pm 0.02$ & $0.67 \pm 0.03$ & $0.70 \pm 0.03$ & $6.0 \pm 0.9$ \\
\hline & & 1800 & (8) & 23.7 & 500 & 401 & 27.8 & 5.4 & 0.53 & $0.46 \pm 0.05$ & $0.81 \pm 0.05$ & 0.74 & $0.59 \pm 0.02$ & $0.66 \pm 0.01$ & $6.7 \pm 0.1$ \\
\hline & & & (9) & 23.8 & 502 & 411 & 22.2 & 4.5 & 0.39 & $0.45 \pm 0.05$ & $0.55 \pm 0.05$ & 0.73 & $0.62 \pm 0.02$ & $0.64 \pm 0.01$ & $6.9 \pm 0.1$ \\
\hline & & & (10) & 22.9 & 501 & 405 & 23.5 & 4.5 & 0.55 & $0.37 \pm 0.05$ & $0.59 \pm 0.05$ & 0.79 & $0.63 \pm 0.02$ & $0.69 \pm 0.01$ & $5.9 \pm 0.1$ \\
\hline & & \multicolumn{2}{|c|}{ Mean \pm SD } & $23.5 \pm 0.5$ & $501 \pm 1$ & $406 \pm 5$ & $24.5 \pm 2.9$ & \begin{tabular}{|l|l|}
$4.8 \pm 0.5$ \\
\end{tabular} & $0.49 \pm 0.09$ & $0.43 \pm 0.05$ & $0.65 \pm 0.14$ & $0.75 \pm 0.03$ & $0.61 \pm 0.02$ & $0.66 \pm 0.03$ & $6.5 \pm 0.5$ \\
\hline \multirow{4}{*}{$\begin{array}{l}\text { H. } \\
\text { Hiber- } \\
\text { nica }\end{array}$} & \multirow{4}{*}{$\mathrm{C}_{3}$} & 700 & (1) & 22.6 & 499 & 404 & 15.2 & 1.2 & 0.08 & $0.21 \pm 0.05$ & $0.36 \pm 0.05$ & 0.41 & $0.23 \pm 0.02$ & 0.30 & $2.4 \pm 0.1$ \\
\hline & & & (2) & 22.8 & 500 & 395 & \begin{tabular}{|l|}
14.8 \\
\end{tabular} & 1.0 & 0.08 & $0.17 \pm 0.05$ & $0.24 \pm 0.05$ & 0.41 & $0.20 \pm 0.02$ & 0.26 & $1.9 \pm 0.1$ \\
\hline & & & (3) & 22.7 & 498 & 395 & 15.8 & 1.3 & 0.09 & $0.21 \pm 0.05$ & $0.31 \pm 0.05$ & 0.42 & $0.23 \pm 0.02$ & 0.29 & $4.9 \pm 0.1$ \\
\hline & & \multicolumn{2}{|c|}{ Mean \pm SD } & $22.7 \pm 0.1$ & $499 \pm 1$ & $398 \pm 5$ & $15.3 \pm 0.5$ & \begin{tabular}{|l|}
$1.2 \pm 0.2$ \\
\end{tabular} & $0.08 \pm 0.01$ & $0.20 \pm 0.02$ & $0.30 \pm 0.06$ & $0.41 \pm 0.01$ & $0.22 \pm 0.02$ & $0.28 \pm 0.02$ & $3.1 \pm 1.6$ \\
\hline \multirow{4}{*}{ Z. mays } & \multirow{4}{*}{$\mathrm{C}_{4}$} & 700 & (1) & 22.0 & 501 & 404 & 28.2 & \begin{tabular}{|l|}
1.8 \\
\end{tabular} & 0.11 & - & $0.65 \pm 0.05$ & 0.23 & - & 0.12 & $19.3 \pm 0.1$ \\
\hline & & & (2) & 21.8 & 499 & 411 & 29.2 & 1.9 & 0.12 & - & $0.58 \pm 0.05$ & 0.26 & - & 0.14 & $20.3 \pm 0.1$ \\
\hline & & & (3) & 22.0 & 501 & 401 & 26.7 & 1.7 & 0.16 & - & $0.49 \pm 0.05$ & 0.48 & - & 0.35 & $21.9 \pm 0.1$ \\
\hline & & \multicolumn{2}{|c|}{ Mean \pm SD } & $21.9 \pm 0.1$ & $500 \pm 1$ & $405 \pm 5$ & $28 \pm 1.3$ & $1.8 \pm 0.1$ & $0.13 \pm 0.03$ & & $0.57 \pm 0.08$ & $0.32 \pm 0.14$ & & $0.20 \pm 0.13$ & $20.5 \pm 1.3$ \\
\hline
\end{tabular}

Table 1. Gas exchange variables and isotopic composition of the bulk leaf water. $T_{\text {leaf: }}$ leaf temperature; $c_{\mathrm{e}}$ : $\mathrm{CO}_{2}$ concentration of the air entering the leaf cuvette; $c_{\mathrm{a}}: \mathrm{CO}_{2}$ concentration of the air inside the cuvette and leaving the cuvette; $A_{\mathrm{n}}$ : net assimilation rate; $E$ : transpiration rate; $g_{s}$ : stomatal conductance for $\mathrm{CO}_{2} ; c_{\mathrm{i}}: \mathrm{CO}_{2}$ concentration in the intercellular airspace; $c_{\mathrm{c}}: \mathrm{CO}_{2}$ concentration in the chloroplasts (site of $\mathrm{CO}_{2}$ uptake); $c_{\mathrm{m}}: \mathrm{CO}_{2}$ concentration in the mesophyll cell; $g_{\mathrm{m} 13}$ : mesophyll conductance from the intercellular airspace to the chloroplasts; $g_{\mathrm{m} 18}$ : mesophyll conductance from the intercellular airspace to the $\mathrm{CO}_{2}-\mathrm{H}_{2} \mathrm{O}$ exchange site; $\delta^{18} \mathrm{O}_{\mathrm{LW}}: \delta^{18} \mathrm{O}$ value of the bulk leaf water vs VSMOW (\%o). The values in bold are mean and standard deviation for the replicates at different light conditions.

$400 \mu \mathrm{mol} \mathrm{mol}{ }^{-1}$. Thus, the decrease in $\mathrm{CO}_{2}$ concentration in the cuvette as a result of uptake by the leaf was about $100 \mu \mathrm{mol} \mathrm{mol}{ }^{-1}$. In typical experiments the air flow rate was between 0.6 and $1.5 \mathrm{~L} \mathrm{~min}^{-1}$ depending on the $\mathrm{CO}_{2}$ uptake rate of the leaf. It generally took $1 \mathrm{~h}$ to reach steady state gas exchange conditions. Gas exchange was measured before and after sampling with an infrared gas analyzer (IRGA) (LI-6262; Li-Cor, Lincoln, NE, USA) operated in the absolute mode. $\mathrm{CO}_{2}$ and $\mathrm{H}_{2} \mathrm{O}$ concentrations of inlet and outlet air were measured subsequently. The IRGA used for $\mathrm{CO}_{2}$ mole fraction measurements, was calibrated every day with compressed air (dry) which has a known $\mathrm{CO}_{2}$ mole fraction, and the reference cell was flushed with $\mathrm{CO}_{2}$-free $\mathrm{N}_{2}$ gas. For the water mole fraction, the IRGA was calibrated using a dew point mirror, and the reference cell was flushed with $\mathrm{CO}_{2}$-free $\mathrm{N}_{2}$ gas. Gas exchange variables were calculated according to von Caemmerer and Farquhar ${ }^{61}$ (see supplementary material Table S1).

The measurements before and after sampling were used to check whether leaves remained sufficiently in steady state over the sampling period, if not, the samples were discarded. The mean value of the two gas exchange measurements (before and after collecting an air sample) were used to calculate the gas exchange parameters. Preparing scrambled $\mathrm{CO}_{2}$ is labor intensive, as a result we used normal $\mathrm{CO}_{2}$ during the gas exchange experiment until reaching steady state. After the steady state was reached (i.e. constant $\mathrm{CO}_{2}$ and $\mathrm{H}_{2} \mathrm{O}$ mole fractions) the $\mathrm{CO}_{2}$ source was switched to the scrambled $\mathrm{CO}_{2}$ supply (Fig. 4) and we waited $15 \mathrm{~min}$ to re-establish steady state conditions. Sampling of air was done by attaching a $\mathrm{Mg}\left(\mathrm{ClO}_{4}\right)_{2}$ dryer (Sigma Aldrich, USA) and 6-L of glass flasks to the outlet of the cuvette. The duration of completely flushing and filling the flasks depended on the flow rate and varied between 20 and $50 \mathrm{~min}$.

We regularly determined the isotopic composition of the entering $\mathrm{CO}_{2}$ by flushing it through an empty leaf cuvette and sampling the air at the outlet as a blank experiment. We used two different synthetic air cylinders spiked with scrambled $\mathrm{CO}_{2}$ : The first cylinder had a $\delta^{13} \mathrm{C}$ value of $-2.50 \pm 0.02 \%$, a $\delta^{18} \mathrm{O}$ value of $25.3 \pm 0.1$ $\%$ and a $\Delta_{47}$ value of $0.24 \pm 0.02 \%$; the second cylinder had a $\delta^{13} \mathrm{C}$ value of $-2.43 \pm 0.03 \%$, a $\delta^{18} \mathrm{O}$ value of $25.5 \pm 0.2 \%$ and a $\Delta_{47}$ value of $0.07 \pm 0.03 \%$ (Table S1, supplementary material). If not indicated differently, these and all further errors reported in this manuscript are $1 \sigma$ standard deviation, determined from repeated analysis of samples.

Automated $\mathrm{CO}_{2}$ extraction from air. We used an automated $\mathrm{CO}_{2}$ extraction and purification system to prepare the sample $\mathrm{CO}_{2}$ for ${ }^{13} \mathrm{C}^{18} \mathrm{O}^{16} \mathrm{O}$ analysis. The system was mainly manufactured from stainless steel parts and consisted of four main units: (i) an air inlet system, (ii) chemical and cryogenic $\mathrm{CO}_{2}$ drying units, (iii) a 


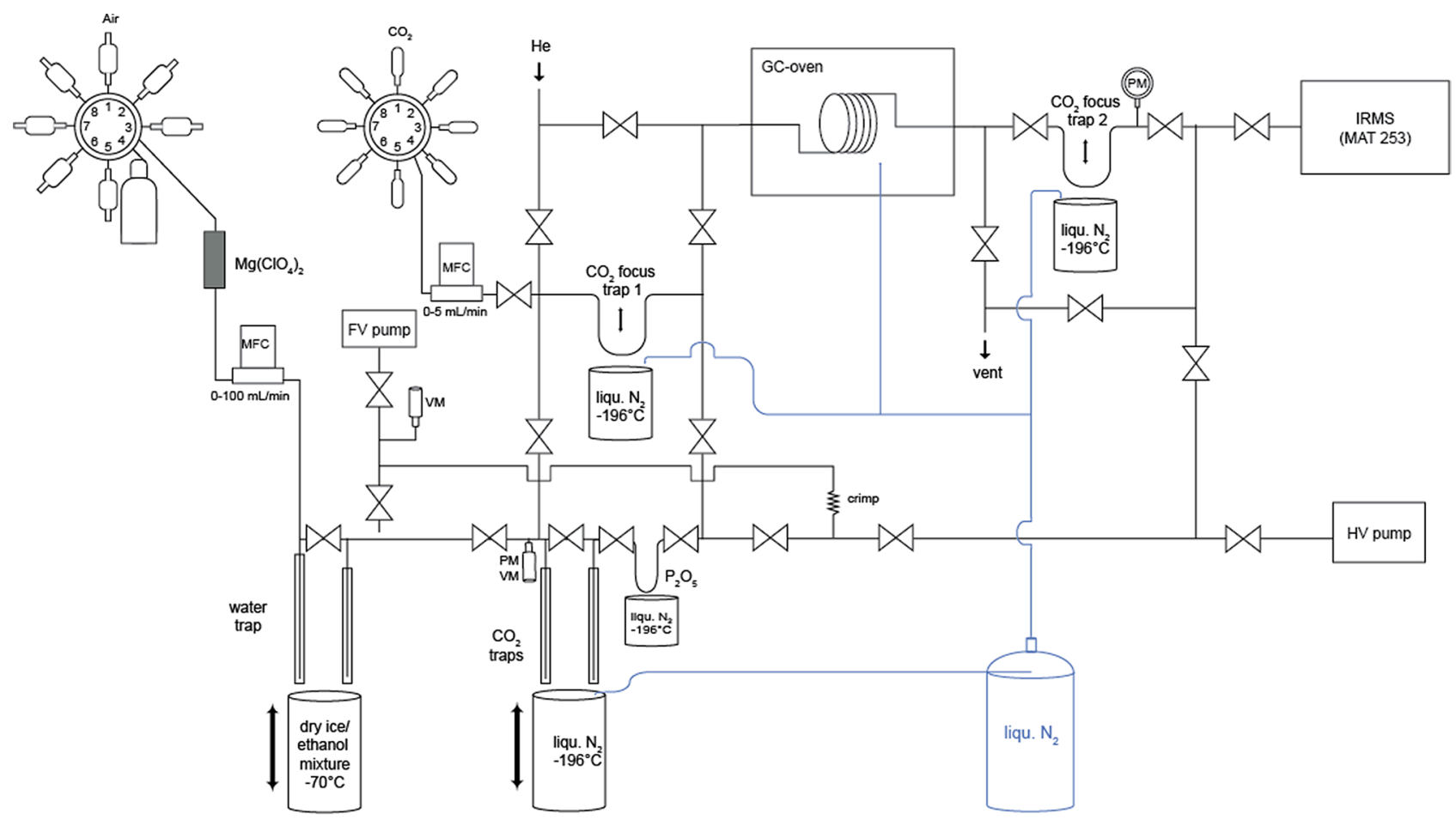

Figure 5. Schematic of the automated system for $\mathrm{CO}_{2}$ extraction from air and purification system. The liquid nitrogen tank is connected to the Dewar using Teflon tube covered with a temperature insulator.

cryogenic $\mathrm{CO}_{2}$ trap and (iv) a GC column for purification (Fig. 5). The outlet of the extraction line was directly connected to the sample bellows of the mass spectrometer. The design of the air inlet system and the cryogenic water and $\mathrm{CO}_{2}$ traps were based on an automated $\mathrm{CO}_{2}$ extraction system dedicated to conventional mass spectrometric isotope analysis of atmospheric $\mathrm{CO}_{2}{ }^{62}$.

The air inlet system allowed connecting several air samples via an 8-port Valco multiport valve: One position of the multiport valve was capped off and was used as a 'closed' position, two positions were generally used for working gas cylinders and the remaining five positions could be used to connect the sample flasks. About $2.5 \mathrm{~L}$ of air were required for one analysis. For a few samples we measured duplicates. Prior to an extraction sequence, the analytical system was evacuated up to the flask valves. The outlet of the multiport valve was connected to a mass flow controller (10-100 $\mathrm{mL} \mathrm{min}^{-1}$; MKS Instruments) to regulate the gas flow during the extraction system. The flow rate was routinely set to $50 \mathrm{~mL} \mathrm{~min}{ }^{-1}$ for extracting the $\mathrm{CO}_{2}$ from air.

In order to minimize exchange with water the gas was thoroughly dried at three different positions in the automated extraction system: (i) before the mass flow controller with a magnesium perchlorate unit, (ii) after the mass flow controller with two cryogenic water traps, and (iii) after the $\mathrm{CO}_{2}$ trap with a phosphorus pentoxide $\left(\mathrm{P}_{2} \mathrm{O}_{5}\right)$ unit. The magnesium perchlorate was filled in a ca. $10 \mathrm{~cm}$ long open-end glass tube with $10 \mathrm{~mm}$ inner diameter in the central part and $1 / 4$ " connectors. The drying agent was held in place with glass wool. The cryogenic water traps were made from $25 \mathrm{~cm}$ long stainless steel tubes with a diameter of $1 / 4$ " and inner tubes with a diameter of $1 / 8 " 63$. The outer tubes were welded tight at the bottom and electropolished afterwards to reobtain a smooth surface. The inner tubes ended about $0.5 \mathrm{~cm}$ above the bottom of the outer tubes to force the air through the entire length of the water trap. To enhance the cold transfer between the outer and inner tube, the inner tubes were slightly bent to touch the outer tubes. The cryogenic water traps were cooled with a mixture of dry ice and ethanol to $-72^{\circ} \mathrm{C}$. The position of the Dewar with the cooling bath was controlled with a hydraulic lift. Due to the relatively large size of the Dewar, the temperature of the cooling bath stayed constant overnight. The $\left(\mathrm{P}_{2} \mathrm{O}_{5}\right)$ drying unit consisted of a $10 \mathrm{~cm}$ long and $6 \mathrm{~mm}$ o.d. wide glass finger containing phosphorous pentoxide $\left(\mathrm{P}_{2} \mathrm{O}_{5}\right)$, which was connected via a $1 / 8^{\prime \prime}$ stainless steel tube to the $\mathrm{CO}_{2}$ trap. It was immersed in liquid nitrogen using a hydraulic lifter.

The chemical drying units were added to the system at a later stage in an attempt to reduce isotopic reequilibration during the extraction process (see below). However, also these additional measures did not prevent partial re-equilibration in the extraction line so that we had to correct all $\Delta_{47}$ data for this partial re-equilibration. The size of the corresponding correction was established by frequently analyzing heated and non-heated $\mathrm{CO}_{2}$ in air standards (see Sect. "Isotopic analysis of $\mathrm{CO}_{2}\left(\delta^{13} \mathrm{C}, \delta^{18} \mathrm{O}\right.$ and $\left.\Delta_{47} "\right)$.

Carbon dioxide (and nitrous oxide) was trapped by immersing the $\mathrm{CO}_{2}$ trap in liquid nitrogen. The design of the carbon dioxide trap and cooling unit was the same as the cryogenic water trap described above. During extraction, the air was processed through the system with a fore vacuum pump. A mechanical flow restriction (crimped 1/16" stainless steel tubing) after the $\mathrm{CO}_{2}$ trap slowed down the flow rate in the $\mathrm{CO}_{2}$ trap. The crimping was adjusted such that the pressure in the water and $\mathrm{CO}_{2}$ trap was about $180 \mathrm{mbar}$ at a flow rate of $50 \mathrm{~mL} \mathrm{~min}^{-1}$. 
After trapping the $\mathrm{CO}_{2}$ in the liquid nitrogen trap, the trap was warmed up to room temperature and the sample $\mathrm{CO}_{2}$ was frozen to the $\mathrm{P}_{2} \mathrm{O}_{5}$ trap. Then, the valve on top of the $\mathrm{P}_{2} \mathrm{O}_{5}$ glass finger was closed and the $\mathrm{CO}_{2}$ was brought to room temperature for final drying for about $10 \mathrm{~min}$. Afterwards, the $\mathrm{CO}_{2}$ was transferred to a $1 / 16^{\prime \prime}$ focusing trap in front of the gas chromatographic column, by immersing this focusing trap in liquid nitrogen. The $\mathrm{CO}_{2}$ was then released into a helium stream at a flow rate of approx. $25 \mathrm{~mL} \mathrm{~min}^{-1}$ through the gas chromatographic (GC) column packed with Porapak Q. The GC column was cooled to $20^{\circ} \mathrm{C}$ during purification with cold nitrogen gas provided from a liquid nitrogen Dewar, to hold back possible hydrocarbon impurities ${ }^{20}$ and it was heated up to $250^{\circ} \mathrm{C}$ in-between extractions. After passing through the GC column, the $\mathrm{CO}_{2}$ was trapped in a second $1 / 16^{\prime \prime}$ trap and the helium was evacuated using the fore and high vacuum pump of the isotope ratio mass spectrometer (IRMS). Finally, the pure $\mathrm{CO}_{2}$ was warmed to room temperature and injected into the mass spectrometer.

The whole $\mathrm{CO}_{2}$ extraction line (including the liquid nitrogen cooling) was controlled via LabVIEW (Version 15.0). The LabVIEW software also gave a signal to the IRMS software Isodat (Version 2.0) to start a measurement. Extraction and purification of one sample took about $4.5 \mathrm{~h}$ and we generally analyzed two working standards and three samples per day.

Isotopic analysis of $\mathrm{CO}_{2}\left(\delta^{13} \mathrm{C}, \delta^{18} \mathrm{O}\right.$ and $\left.\Delta_{47}\right)$. Mass spectrometric analysis of the isotopic composition of the extracted and purified $\mathrm{CO}_{2}$ was carried out in dual inlet mode on a MAT 253 mass spectrometer (Thermo Fisher Scientific, Germany) with a modified collector unit that allowed simultaneous analysis of the mass-tocharge ratios $(\mathrm{m} / \mathrm{z}) 44,45,46,47,48$ and 49 . The overall reproducibility for $\Delta_{47}$ analysis was about $0.04 \%$, determined from replicate measurements of the compressed air cylinder.

The mass spectrometric $\Delta_{47}$ measurements were calibrated relative to $\mathrm{CO}_{2}$ heated to $1000{ }^{\circ} \mathrm{C}$ and $\mathrm{CO}_{2}$ equilibrated with water at $28^{\circ} \mathrm{C}^{25,64}$. We analyzed heated and water equilibrated $\mathrm{CO}_{2}$ with a different bulk isotopic composition and determined a slope of 0.0024 for the heated and water-equilibrated gas line (Figure S3, supplementary material). This slope was used to correct for small, negative background effects on $\mathrm{m} / \mathrm{z} 47$. The bulk isotopic composition of our in-house reference $\mathrm{CO}_{2}$ gas was $\delta^{13} \mathrm{C}_{\mathrm{VPDB}}=-2.82 \%$ and $\delta^{18} \mathrm{O}_{\mathrm{VSMOW}}=-26.11 \%$ and the maximum $\delta^{47}$ difference between the sample and the reference $\mathrm{CO}_{2}$ was $17 \%$ resulting in a maximum $\Delta_{47}$ bulk isotope composition effect $-0.04 \%$ which is corrected based on heated and equilibration gas slope.

In order to calibrate our $\delta^{13} \mathrm{C}, \delta^{18} \mathrm{O}$ and $\Delta_{47}$ measurements of $\mathrm{CO}_{2}$ in air, we prepared two cylinders of $\mathrm{CO}_{2}$ in synthetic air as working reference cylinders (Table S2). The first synthetic air cylinder was spiked with $\mathrm{CO}_{2}$ resulting in a concentration of about $500 \mu \mathrm{mol} \mathrm{mol}^{-1}, \delta^{13} \mathrm{C}_{\mathrm{VPDB}}=-2.76 \%{ }_{0}, \delta^{18} \mathrm{O}_{\mathrm{VSMOW}}=25.65 \%$ and $\Delta_{47}=0.82$ $\%$. For the second synthetic air cylinder we used scrambled $\mathrm{CO}_{2}$ with a similar bulk isotopic composition, i.e. $\delta^{13} \mathrm{C}_{\mathrm{VPDB}}=-2.73 \%$ o, $\delta^{18} \mathrm{O}_{\mathrm{VSMOW}}=-25.83 \%$ but a low clumped isotope signature of $\Delta_{47}=0.11 \%$ and a $\mathrm{CO}_{2}$ concentration of $400 \mu \mathrm{mol} \mathrm{mol}{ }^{-1}$.

The clumped isotopic composition of the first air cylinder was determined by analyzing the pure $\mathrm{CO}_{2}$ directly in the dual inlet system of the IRMS versus the heated and water equilibrated $\mathrm{CO}_{2}$ samples and versus $\mathrm{CO}_{2}$ obtained by acid digestion at $70^{\circ} \mathrm{C}$ from a set of clumped isotope carbonate standards (ETH1, ETH2, ETH3 and ETH4). Both procedures gave consistent results of $\Delta_{47}=0.82 \pm 0.04 \%$. The same $\mathrm{CO}_{2}$ was then mixed in reference air cylinder 1 with synthetic air. After extracting and purifying the $\mathrm{CO}_{2}$, we found an average $\Delta_{47}$ value of $0.86 \pm 0.04 \%$. The reason for this offset of $0.04 \pm 0.04 \%$ might be partial re-equilibration within the extraction line, where full equilibration at room temperature would result in $\Delta_{47}=0.93 \%$.

For preparing the second air cylinder, we heated the pure $\mathrm{CO}_{2}$ to $1000{ }^{\circ} \mathrm{C}$ for more than 2 hours ${ }^{64}$ and then mixed it into synthetic, $\mathrm{CO}_{2}$-free air. After extracting and purifying the $\mathrm{CO}_{2}$ from the second cylinder, we determined an average $\Delta_{47}$ value of $0.42 \pm 0.04 \%$. The reason for this significant deviation from the expected $\Delta_{47}$ value of $0.03 \%$ is most likely twofold: (i) partial re-equilibration during mixing of scrambled $\mathrm{CO}_{2}$ with synthetic air, and (ii) partial re-equilibration in the automated $\mathrm{CO}_{2}$ extraction line. Subsequently, we prepared several other mixtures of heated $\mathrm{CO}_{2}$ with an expected clumped isotope signature of $\Delta_{47}=0.03 \%$ in synthetic air cylinders. For all cylinders that were prepared this way we found $\Delta_{47}$ values that were at least $+0.26 \%$ enriched in $\Delta_{47}$ relative to the expected value. It is not straightforward to decide whether the clumped signal of a $\mathrm{CO}_{2}$-in-air standard was altered during the preparation of the air standard or during the $\mathrm{CO}_{2}$ extraction step. Comparison between the $\Delta_{47}$ of the pure $\mathrm{CO}_{2}$ and $\Delta_{47}$ value after processing the $\mathrm{CO}_{2}$-air mixtures through the $\mathrm{CO}_{2}$ extraction line reveals a $\Delta_{47}$ scale contraction of $24 \%$, i.e. we measure only $76 \%$ of the true difference between samples when determining the clumped isotopic composition of $\mathrm{CO}_{2}$ in air. This apparent scale contraction was highly reproducible over the course of the experiments reported here and we corrected all $\Delta_{47}$ values accordingly. This illustrates that referencing $\Delta_{47}$ measurements for atmospheric $\mathrm{CO}_{2}$ samples is challenging because there is no $\Delta_{47}$ standard for $\mathrm{CO}_{2}$-in-air studies available.

The leaf gas exchange samples contained up to about $0.3 \mu \mathrm{mol} \mathrm{mol}{ }^{-1} \mathrm{~N}_{2} \mathrm{O}$. All $\mathrm{CO}_{2}$ isotope measurements of $\delta^{13} \mathrm{C}, \delta^{18} \mathrm{O}$ and $\Delta_{47}$ were corrected for the mass interference from the $\mathrm{N}_{2} \mathrm{O}$ isotopologues because $\mathrm{N}_{2} \mathrm{O}$ was not separated from $\mathrm{CO}_{2}$ during the purification step. The amount of $\mathrm{N}_{2} \mathrm{O}$ was inferred from the intensity of the $\mathrm{N}$ fragment at $\mathrm{m} / \mathrm{z} 14$ relative to the intensity of $\mathrm{m} / \mathrm{z} 44^{20}$. For typical $\mathrm{N}_{2} \mathrm{O}$ mole fractions of $0.3 \mu \mathrm{mol} \mathrm{mol}^{-1}$, the $\mathrm{N}_{2} \mathrm{O}$ correction was approximately $+0.17 \%$ for $\delta^{13} \mathrm{C},+0.45 \%$ for $\delta^{18} \mathrm{O}$ and $-0.13 \%$ for $\Delta_{47}$.

Considering all correction procedures, most notable the $24 \% \Delta_{47}$ scale contraction, we obtain an overall reproducibility for repeated extraction of $\mathrm{CO}_{2}$ from air and subsequent isotopic analysis of $0.08 \% 0$ for $\delta^{13} \mathrm{C}, 0.3$ $\%$ for $\delta^{18} \mathrm{O}$ and $0.045 \%$ for $\Delta_{47}$.

Leaf water extraction and $\boldsymbol{\delta}^{\mathbf{1 8}} \mathrm{O}$ analysis. Immediately after sampling of air for $\Delta_{47}$ measurements, the leaf was placed between plastic sheets, its area was measured, and it was enclosed in a vial and frozen. Leaf water was extracted from the leaves by cryogenic vacuum distillation, i.e. the leaf sample was heated in vacuum 


\begin{tabular}{|c|c|c|c|c|c|c|c|c|c|c|c|c|}
\hline Species & PPFD & No. $\exp$ & Cyl & $\delta^{13} \mathrm{C}_{e}$ & $\delta^{13} \mathrm{C}_{a}$ & $\Delta_{\mathrm{A}}{ }^{13} \mathrm{C}$ & $\delta^{18} \mathrm{O}_{e}$ & $\delta^{18} \mathrm{O}_{a}$ & $\Delta_{\mathrm{A}}{ }^{18} \mathrm{O}$ & $\Delta_{47 \mathrm{e}}$ & $\Delta_{47 \mathrm{a}}$ & $\Delta_{\mathrm{A}} \Delta_{47}$ \\
\hline \multirow{14}{*}{ H. annuus } & 200 & (1) & I & $-2.50 \pm 0.02$ & $0.99 \pm 0.06$ & $22.5 \pm 0.3$ & $25.3 \pm 0.1$ & $36.2 \pm 0.3$ & $71 \pm 2$ & $0.24 \pm 0.02$ & $0.54 \pm 0.05$ & $1.9 \pm 0.3$ \\
\hline & & (2) & I & $-2.50 \pm 0.02$ & $1.20 \pm 0.06$ & $22.5 \pm 2.3$ & $25.3 \pm 0.1$ & $39.2 \pm 0.3$ & $77 \pm 2$ & $0.24 \pm 0.02$ & $0.61 \pm 0.05$ & $2.0 \pm 0.3$ \\
\hline & & (3) & I & $-2.50 \pm 0.02$ & $1.73 \pm 0.06$ & \begin{tabular}{|l|}
$23.5 \pm 0.3$ \\
\end{tabular} & $25.3 \pm 0.1$ & \begin{tabular}{|l|l|}
$40.0 \pm 0.3$ \\
\end{tabular} & $84 \pm 2$ & $0.24 \pm 0.02$ & $0.68 \pm 0.05$ & $2.4 \pm 0.3$ \\
\hline & Mean \pm SD & & -2.50 & $1.31 \pm 0.38$ & $22.8 \pm 0.6$ & 25.3 & $38.5 \pm 2$ & $77.3 \pm 7$ & 0.24 & $0.61 \pm 0.07$ & $2.10 \pm 0.26$ & \\
\hline & 700 & (4) & I & $-2.50 \pm 0.02$ & $1.78 \pm 0.06$ & \begin{tabular}{|l|l|}
$21.6 \pm 0.3$ \\
\end{tabular} & $25.3 \pm 0.1$ & \begin{tabular}{|l|l|}
$36.3 \pm 0.3$ \\
\end{tabular} & $56 \pm 2$ & $0.24 \pm 0.02$ & $0.48 \pm 0.05$ & $1.2 \pm 0.3$ \\
\hline & & (5) & I & $-2.50 \pm 0.02$ & $1.22 \pm 0.06$ & $20.5 \pm 0.3$ & $25.3 \pm 0.1$ & $34.8 \pm 0.3$ & $52 \pm 2$ & $0.24 \pm 0.02$ & $0.58 \pm 0.05$ & $1.9 \pm 0.3$ \\
\hline & & (6) & I & $-2.50 \pm 0.02$ & $1.51 \pm 0.06$ & $21.3 \pm 0.3$ & $25.3 \pm 0.1$ & $35.8 \pm 0.3$ & $56 \pm 2$ & $0.24 \pm 0.02$ & $0.57 \pm 0.05$ & $1.7 \pm 0.3$ \\
\hline & & (7) & I & $-2.50 \pm 0.02$ & $1.65 \pm 0.06$ & $22.5 \pm 0.3$ & $25.3 \pm 0.1$ & $36.8 \pm 0.3$ & $63 \pm 2$ & $0.24 \pm 0.02$ & $0.61 \pm 0.05$ & $2.0 \pm 0.3$ \\
\hline & Mean \pm SD & & & -2.50 & $1.54 \pm 0.24$ & $21.5 \pm 0.8$ & 25.3 & \begin{tabular}{|l|l}
$35.9 \pm 0.9$ \\
\end{tabular} & $56.8 \pm 5$ & \begin{tabular}{|l|l|}
0.24 \\
\end{tabular} & $0.56 \pm 0.06$ & $1.7 \pm 0.36$ \\
\hline & & & & -2.50 & $1.54 \pm 0.24$ & \begin{tabular}{|l|l|}
$21.5 \pm 0.8$ \\
\end{tabular} & 25.3 & \begin{tabular}{|l|}
$35.9 \pm 0.9$ \\
\end{tabular} & $56.8 \pm 5$ & 0.24 & $0.56 \pm 0.06$ & $1.70 \pm 0.36$ \\
\hline & 1800 & (8) & I & $-2.50 \pm 0.02$ & $1.34 \pm 0.06$ & $\mid 19.8 \pm 0.3$ & $25.3 \pm 0.1$ & $35.6 \pm 0.3$ & $53 \pm 2$ & $0.24 \pm 0.02$ & $0.45 \pm 0.05$ & $1.1 \pm 0.3$ \\
\hline & & (9) & I & $-2.50 \pm 0.02$ & $1.18 \pm 0.06$ & $20.4 \pm 0.3$ & $25.3 \pm 0.1$ & $34.6 \pm 0.3$ & $53 \pm 2$ & $0.24 \pm 0.02$ & $0.50 \pm 0.05$ & $1.3 \pm 0.3$ \\
\hline & & (10) & I & $-2.50 \pm 0.02$ & $1.52 \pm 0.06$ & \begin{tabular}{|l|}
$21.3 \pm 0.3$ \\
\end{tabular} & $25.3 \pm 0.1$ & $35.8 \pm 0.3$ & $56 \pm 2$ & $0.24 \pm 0.02$ & $0.55 \pm 0.05$ & $1.6 \pm 0.3$ \\
\hline & Mean \pm SD & & -2.50 & $1.35 \pm 0.17$ & $20.5 \pm 0.8$ & 25.3 & $35.3 \pm 0.6$ & $54 \pm 2$ & 0.24 & $0.50 \pm 0.05$ & $1.33 \pm 0.25$ & \\
\hline \multirow{4}{*}{ H.hibernica } & 700 & (1) & I & $-2.50 \pm 0.02$ & $-0.53 \pm 0.06$ & \begin{tabular}{|l|l|}
$10.5 \pm 0.3$ \\
\end{tabular} & \begin{tabular}{|l|}
$25.3 \pm 0.1$ \\
\end{tabular} & \begin{tabular}{|l|l|}
$28.8 \pm 0.3$ \\
\end{tabular} & $18 \pm 2$ & $0.24 \pm 0.02$ & $0.25 \pm 0.05$ & $0.0 \pm 0.3$ \\
\hline & & (2) & I & $-2.50 \pm 0.02$ & $-0.64 \pm 0.06$ & $9.4 \pm 0.3$ & \begin{tabular}{|l|}
$25.3 \pm 0.1$ \\
\end{tabular} & \begin{tabular}{|l|l|}
$28.4 \pm 0.3$ \\
\end{tabular} & $15 \pm 2$ & $0.24 \pm 0.02$ & $0.29 \pm 0.05$ & $0.3 \pm 0.3$ \\
\hline & & (3) & I & $-2.50 \pm 0.02$ & $-0.35 \pm 0.06$ & \begin{tabular}{|l|}
$10.5 \pm 0.3$ \\
\end{tabular} & $25.3 \pm 0.1$ & \begin{tabular}{|l|}
$29.2 \pm 0.3$ \\
\end{tabular} & $19 \pm 2$ & $0.24 \pm 0.02$ & $0.12 \pm 0.05$ & $-0.5 \pm 0.3$ \\
\hline & Mean \pm SD & & & $-0.51 \pm 0.15$ & $10.13 \pm 0.6$ & 25.3 & $28.80 \pm 0.4$ & $17.33 \pm 2$ & 0.24 & $0.22 \pm 0.09$ & $-0.07 \pm 0.4$ & \\
\hline \multirow{4}{*}{ Z. mays } & 700 & (1) & II & $-2.43 \pm 0.03$ & $-1.75 \pm 0.06$ & $3.5 \pm 0.3$ & $25.5 \pm 0.2$ & \begin{tabular}{|l|l|}
$28.4 \pm 0.3$ \\
\end{tabular} & $15 \pm 2$ & $0.07 \pm 0.03$ & $0.07 \pm 0.05$ & $0.0 \pm 0.3$ \\
\hline & & (2) & II & $-2.43 \pm 0.03$ & $-1.75 \pm 0.06$ & $3.9 \pm 0.3$ & $25.5 \pm 0.2$ & $28.3 \pm 0.3$ & $16 \pm 2$ & $0.07 \pm 0.03$ & $0.05 \pm 0.05$ & $-0.1 \pm 0.3$ \\
\hline & & (3) & II & $-2.43 \pm 0.03$ & $-1.78 \pm 0.06$ & $3.3 \pm 0.3$ & $25.5 \pm 0.2$ & \begin{tabular}{|l|l|}
$31.6 \pm 0.3$ \\
\end{tabular} & $31 \pm 2$ & $0.07 \pm 0.03$ & $0.05 \pm 0.05$ & $-0.1 \pm 0.3$ \\
\hline & Mean \pm SD & & -2.43 & $-1.76 \pm 0.02$ & $3.57 \pm 0.31$ & 25.5 & $29.43 \pm 1.9$ & \begin{tabular}{|l|}
$20.67 \pm 9$ \\
\end{tabular} & \begin{tabular}{|l|}
0.07 \\
\end{tabular} & $0.06 \pm 0.01$ & $-0.07 \pm 0.06$ & \\
\hline
\end{tabular}

Table 2. Isotopic composition of the $\mathrm{CO}_{2}$ entering and leaving the leaf cuvette and the resulting isotopic discrimination against the isotopologues ${ }^{13} \mathrm{C}^{16} \mathrm{O}^{16} \mathrm{O},{ }^{12} \mathrm{C}^{18} \mathrm{O}^{16} \mathrm{O}$ and ${ }^{13} \mathrm{C}^{18} \mathrm{O}^{16} \mathrm{O}$ given as $\Delta_{\mathrm{A}}{ }^{13} \mathrm{C}, \Delta_{\mathrm{A}}{ }^{18} \mathrm{O}$ and $\Delta_{\mathrm{A}} \Delta_{47}$. All the isotope and discrimination values are reported in per mill (\%o), with respect to VPDB (for $\delta^{13} \mathrm{C}$ ) and VSMOW (for $\delta^{18} \mathrm{O}$ ). The values in bold are mean and standard deviation for the replicates at different light conditions.

to $60{ }^{\circ} \mathrm{C}$ and the evaporated water was directly frozen in a vial cooled to liquid nitrogen temperature ${ }^{13}$. The distillation process was carried out for at least $4 \mathrm{~h}$ to ensure quantitative extraction (West et al., 2006). The $\delta^{18} \mathrm{O}$ value of the leaf water was determined by equilibrating $\mathrm{CO}_{2}$ and water in a GasBench II (Thermo Scientific), and subsequent analysis of the oxygen isotope composition of the equilibrated $\mathrm{CO}_{2}$ with a Delta V mass spectrometer (Thermo Scientific, Germany). The oxygen isotope composition was calibrated versus VSMOW and SLAP.

\section{Results}

Gas exchange data and isotopic composition of leaf water. Gas exchange of Helianthus was characterized by high stomatal conductance relative to the other two species (Table 1). The net assimilation $A_{\mathrm{n}}$ was $12 \mu \mathrm{mol} \mathrm{m} \mathrm{m}^{-2}$ at a PPFD of $200 \mu \mathrm{mol} \mathrm{m} \mathrm{m}^{-2} \mathrm{~s}^{-1}$ and increased to $22 \mu \mathrm{mol} \mathrm{m}{ }^{-2} \mathrm{~s}^{-1}$ at $700 \mu \mathrm{mol} \mathrm{m}^{-2} \mathrm{~s}^{-1}$. The net assimilation increased only little further when measured at a PPFD of $1800 \mu \mathrm{mol} \mathrm{m}^{-2} \mathrm{~s}^{-1}\left(25 \mu \mathrm{mol} \mathrm{m}^{-2} \mathrm{~s}^{-1}\right) \cdot c_{\mathrm{i}} / c_{\mathrm{a}}$ decreased with increasing irradiance, from 0.82 (at PPFD of $200 \mu \mathrm{mol} \mathrm{m}{ }^{-2} \mathrm{~s}^{-1}$ ) to 0.75 (at $1800 \mu \mathrm{mol} \mathrm{m}^{-2} \mathrm{~s}^{-1}$ ).

Hedera was measured at a PPFD of $700 \mu \mathrm{mol} \mathrm{m} \mathrm{m}^{-2} \mathrm{~s}^{-1}$ only where $A_{\mathrm{n}}$ was lower than that of the other two species $\left(15 \mu \mathrm{mol} \mathrm{m}^{-2} \mathrm{~s}^{-1}\right)$. Compared to Helianthus at the same PPFD, the stomatal conductance $g_{\mathrm{s}}$ was much lower $\left(0.08 \mathrm{~mol} \mathrm{~m}^{-2} \mathrm{~s}^{-1}\right)$, causing a clearly lower $c_{\mathrm{i}} / c_{\mathrm{a}}$ ratio $(0.41)$ (Table 1$)$. The $\mathrm{C}_{4}$ species Zea was also measured at $700 \mu \mathrm{mol} \mathrm{m}^{-2} \mathrm{~s}^{-1}$ only where $A_{\mathrm{n}}$ was the highest of the three $\left(28 \mu \mathrm{mol} \mathrm{m} \mathrm{m}^{-2}\right)$ but $g_{\mathrm{s}}$ was rather low $\left(0.13 \mathrm{~mol} \mathrm{~m}^{-2} \mathrm{~s}^{-1}\right)$ causing the lowest $c_{\mathrm{i}} / c_{\mathrm{a}}$ ratio of the three species, $(0.32)$ (Table 1$)$.

For Helianthus, mesophyll conductance calculated using $\Delta_{\mathrm{A}}{ }^{13} \mathrm{C}\left(g_{\mathrm{m} 13}\right)$ increased with light intensity whereas the mesophyll conductance measured using $\Delta_{\mathrm{A}}{ }^{18} \mathrm{O}\left(g_{\mathrm{m} 18}\right)$ did not show a clear correlation with the light intensity (Table 1 and Figure S2). Our estimates of $g_{\mathrm{m} 18}$ had relatively larger errors compared to $g_{\mathrm{m} 13}$ (Table 1 ) and the values were larger (Table 1). For Helianthus, the $g_{\mathrm{m} 18}$ estimates were 1.3 to 2.5 times larger and for Hedera 1.5 times.

The $\delta^{18} \mathrm{O}$ value of the bulk leaf water of Helianthus varied between 4.3 and $6.9 \%$ with an average value of $6 \pm 1 \%$. For Hedera, the bulk leaf water isotopic composition was $\delta^{18} \mathrm{O}=3.1 \pm 1.6 \%$. The relative difference in the $\delta^{18} \mathrm{O}$ value of the bulk leaf water between the Helianthus and Hedera is due to the difference in the $\delta^{18} \mathrm{O}$ of source water. For Zea, the bulk leaf water isotopic composition of the leaf part inserted in the cuvette was $\delta^{18} \mathrm{O}=20.5 \pm 1.3 \%$. We used a section of the Zea leaves at about $1 / 3$ from the tip for gas exchange experiments and such high enrichments in $\delta^{18} \mathrm{O}$ of leaf water compared to the source water are typical for sections towards the tip of elongated leaves $\left(\right.$ see, ${ }^{65}$ ) and at higher vapor pressure deficit ${ }^{66}$.

Effect of photosynthetic gas exchange on the isotopic composition of $\mathrm{CO}_{2}$. For Helianthus $\Delta_{47}$ increased from $0.24 \%$ in the incoming air to $0.50 \%$ to $0.61 \%$ in the outgoing air, at a $c_{\mathrm{m}} / c_{\mathrm{a}}$ ratio of 0.66 to 

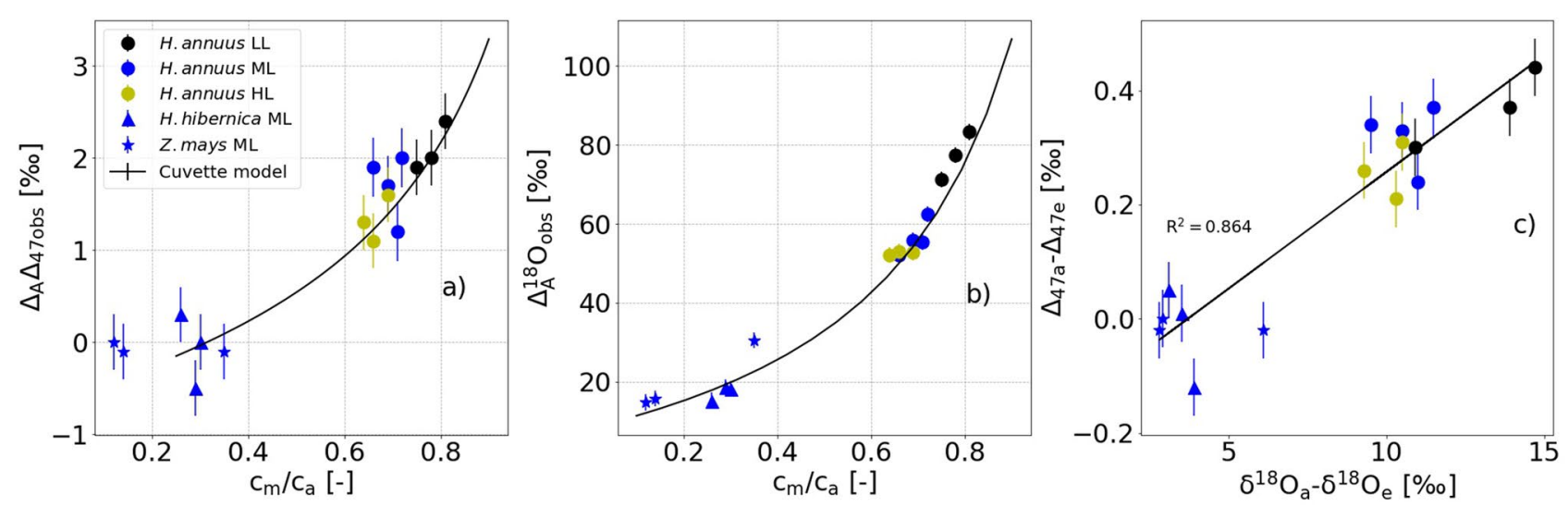

Figure 6. Effect of photosynthetic gas exchange on $\Delta_{47}$ and $\delta^{18} \mathrm{O}$ of $\mathrm{CO}_{2} . \Delta_{\mathrm{A}} \Delta_{47}(\mathbf{a})$ and $\Delta_{\mathrm{A}}{ }^{18} \mathrm{O}$ (b) during photosynthetic gas exchange experiments as a function of the $c_{\mathrm{m}} / c_{\mathrm{a}}$ ratio. (LL = low light: PPFD $=200 \mu \mathrm{mol} \mathrm{m}^{-2} \mathrm{~s}^{-1}, \mathrm{ML}=$ medium light: $\mathrm{PPFD}=700 \mu \mathrm{mol} \mathrm{m}{ }^{-2} \mathrm{~s}^{-1}, \mathrm{HL}=$ high light: $\left.\mathrm{PPFD}=1800 \mu \mathrm{mol} \mathrm{m}{ }^{-2} \mathrm{~s}^{-1}\right)$. a) discrimination against ${ }^{13} \mathrm{C}^{18} \mathrm{O}^{16} \mathrm{O}\left(\Delta_{\mathrm{A}} \Delta_{47}\right)$. (b) discrimination against ${ }^{12} \mathrm{C}^{18} \mathrm{O}^{16} \mathrm{O}$ $\left(\Delta_{\mathrm{A}}{ }^{18} \mathrm{O}\right)$. (c) Relative difference between $\Delta_{47}$ the $\mathrm{CO}_{2}$ entering and leaving the cuvette as a function of the difference between $\delta^{18} \mathrm{O}$ of $\mathrm{CO}_{2}$ entering and leaving the cuvette. The solid line is a linear regression fit with a function of $\left(\Delta_{47 \mathrm{a}}-\Delta_{47 \mathrm{a}}\right)=(0.041 \pm 0.004) \times\left(\delta^{18} \mathrm{Oa}-\delta^{18} \mathrm{Oe}\right)-0.151 \pm 0.040$. For the leaf cuvette model, we assumed $\delta^{18} \mathrm{O}=10 \%$ for the leaf water and a mesophyll conductance of $0.5 \mathrm{~mol} \mathrm{~m}^{-2} \mathrm{~s}^{-1} \mathrm{bar}^{-1}$.

0.78 (Table 1 and 2). For Hedera, at a $c_{\mathrm{m}} / c_{\mathrm{a}}$ ratio of 0.28 , the change in $\Delta_{47}$ between incoming and outgoing air was more variable than for the other species at similar light intensity. The average change of all the experiments under similar conditions is insignificant (from $0.24 \%$ to $0.22 \%$ ). For Zea, at lower $c_{\mathrm{m}} / c_{\mathrm{a}}$ ratio $(0.20)$, results were more consistent and no statistically significant decrease in $\Delta_{47}$ between incoming and outgoing air was observed (Table 1 and 2).

When these changes are converted to discrimination $\left(\Delta_{\mathrm{A}} \Delta_{47}\right)$, for Helianthus, we observed an average $\Delta_{\mathrm{A}} \Delta_{47}$ of $1.7 \pm 0.4 \%$. Slightly negative but non-significant discriminations were observed for Hedera $(-0.07 \pm 0.4 \%)$, and Zea $\left(-0.07 \pm 0.06 \%\right.$ ) (Fig. 6a, Table 2). The $\Delta_{\mathrm{A}} \Delta_{47}$ correlates strongly with the $c_{\mathrm{m}} / c_{\mathrm{a}}$ ratio, higher $\Delta_{\mathrm{A}} \Delta_{47}$ are observed at higher $c_{\mathrm{m}} / c_{\mathrm{a}}$ ratio. The change in $\Delta_{47}$ between $\mathrm{CO}_{2}$ entering and leaving the cuvette correlates strongly with the change in $\delta^{18} \mathrm{O}$ of $\mathrm{CO}_{2}$ entering and leaving the cuvette, with an $\mathrm{R}^{2}$ value of 0.864 (Fig. $6 \mathrm{c}$ ). The positive correlation between $\Delta_{47}$ and $\delta^{18} \mathrm{O}$ of $\mathrm{CO}_{2}$ indicates that photosynthetic gas exchange affects $\Delta_{47}$ and $\delta^{18} \mathrm{O}$ similarly (Fig. 6a).

In addition to the $\Delta_{\mathrm{A}} \Delta_{47}$, we also measured $\Delta_{\mathrm{A}}{ }^{13} \mathrm{C}$ and $\Delta_{\mathrm{A}}{ }^{18} \mathrm{O}$ (Table 2). The average net carbon isotope discrimination was $\Delta_{\mathrm{A}}{ }^{13} \mathrm{C}=21.6 \pm 1.2 \%$ for Helianthus, $10.1 \pm 0.7 \%$ for Hedera and $3.6 \pm 0.3 \%$ for Zea. The magnitude of $\Delta_{\mathrm{A}}{ }^{13} \mathrm{C}$ also correlates with the $c_{\mathrm{c}} / c_{\mathrm{a}}$ ratio, in agreement with previous studies ${ }^{13,42,48}$. As $c_{\mathrm{c}} / c_{\mathrm{a}}$ depends on light intensity, the gas exchange experiments with Helianthus show a slightly higher $\Delta_{\mathrm{A}}{ }^{13} \mathrm{C}$ at low light intensity $(22.8 \pm 0.6 \%$ o compared to mid and high light conditions $(21.1 \pm 0.9 \%$ o). The average apparent oxygen isotope discrimination $\Delta_{\mathrm{A}}{ }^{18} \mathrm{O}$ was $62 \pm 12 \%$ for Helianthus, $18 \pm 3 \%$ for Hedera and $21 \pm 9 \%$ for Zea. Similar to $\Delta_{\mathrm{A}}{ }^{13} \mathrm{C}, \Delta_{\mathrm{A}}{ }^{18} \mathrm{O}$ is higher at low light intensities $(78 \pm 6 \%$ ) compared to mid and high light conditions $(55 \pm 4$ $\%$ ) (Table 2, Fig. 6b).

\section{Discussion}

The $\Delta_{47}$ value of $\mathrm{CO}_{2}$ has been suggested as a possible tracer for gross primary production, however two previous studies presented contradicting conclusions on the effect of photosynthesis on the $\Delta_{47}$ value of $\mathrm{CO}_{2}{ }^{19,22}$. In this study, using a leaf cuvette experiment under controlled conditions (light, $\mathrm{CO}_{2}$, temperature and humidity) and a leaf cuvette model, we showed that photosynthetic gas exchange can in principle increase or decrease the $\Delta_{47}$ value of $\mathrm{CO}_{2}$ depending on the $\Delta_{47}$ value of the $\mathrm{CO}_{2}$ entering the leaf, the $\mathrm{CO}_{2}-\mathrm{H}_{2} \mathrm{O}$ exchange temperature and the back-diffusion flux (quantified as $c_{\mathrm{m}} / c_{\mathrm{a}}$ ratio). However, under conditions similar for the current atmosphere, photosynthesis depletes the $\Delta_{47}$ value of atmospheric $\mathrm{CO}_{2}$.

The photosynthetic effect on $\Delta_{47}$ of the residual $\mathrm{CO}_{2}$ for the $\mathrm{C}_{3}$ species Helianthus and Hedera correlated with the $\mathrm{CO}_{2}$ concentration gradient over the leaf, i.e. $c_{\mathrm{m}} / c_{\mathrm{a}}$, and the discrimination in $\Delta_{47}$ showed a similar pattern to $\Delta_{\mathrm{A}}{ }^{18} \mathrm{O}$ (Fig. 6). The main driver for the discrimination against $\delta^{18} \mathrm{O}$ and $\Delta_{47}$ values of $\mathrm{CO}_{2}$ is isotope exchange with leaf water, and the fractionation associated with the initial fixation by the enzyme RuBisCO (Ribulose1,5-bisphosphate carboxylase-oxygenase) or PEP (Phosphoenolpyruvate) has no/negligible effect on the $\delta^{18} \mathrm{O}$ and $\Delta_{47}$ value of $\mathrm{CO}_{2} . \Delta_{47}$ value is independent of fractionations in the bulk isotope composition (i.e., variations in $\delta^{18} \mathrm{O}$ value due to isotope exchange with leaf water and changes in $\delta^{13} \mathrm{C}$ due to metabolic carbon fixation). The lower discrimination in $\Delta_{47}$ by $\mathrm{C}_{4}$ plant $Z e a$ is due to the lower back-diffusion flux (lower conductance and higher assimilation rate) and the fractionation is dominated by diffusion in agreement with the hypothesis of Eiler and Schauble ${ }^{19}$. Gas phase diffusion causes a decrease in $\Delta_{47}$ of the residual $\mathrm{CO}_{2}{ }^{19}$, see also Fig. 7 .

For Helianthus, at a $c_{\mathrm{m}} / c_{\mathrm{a}}$ ratio of 0.81 , we observed an increase in $\Delta_{47}$ from $0.24 \%$ to $0.68 \%$ (an increase by $0.44 \%$ ) for a $\mathrm{CO}_{2}$ drawdown of $100 \mu \mathrm{mol} \mathrm{mol}^{-1}$. Eiler and Schauble ${ }^{19}$ reported an increase in $\Delta_{47}$ from 0.65 to 0.75 (an increase by $0.1 \%$, i.e. $\Delta_{\mathrm{A}} \Delta_{47} \sim 0.54 \%$ ) due to photosynthetic gas exchange for a $\mathrm{CO}_{2}$ drawdown of 

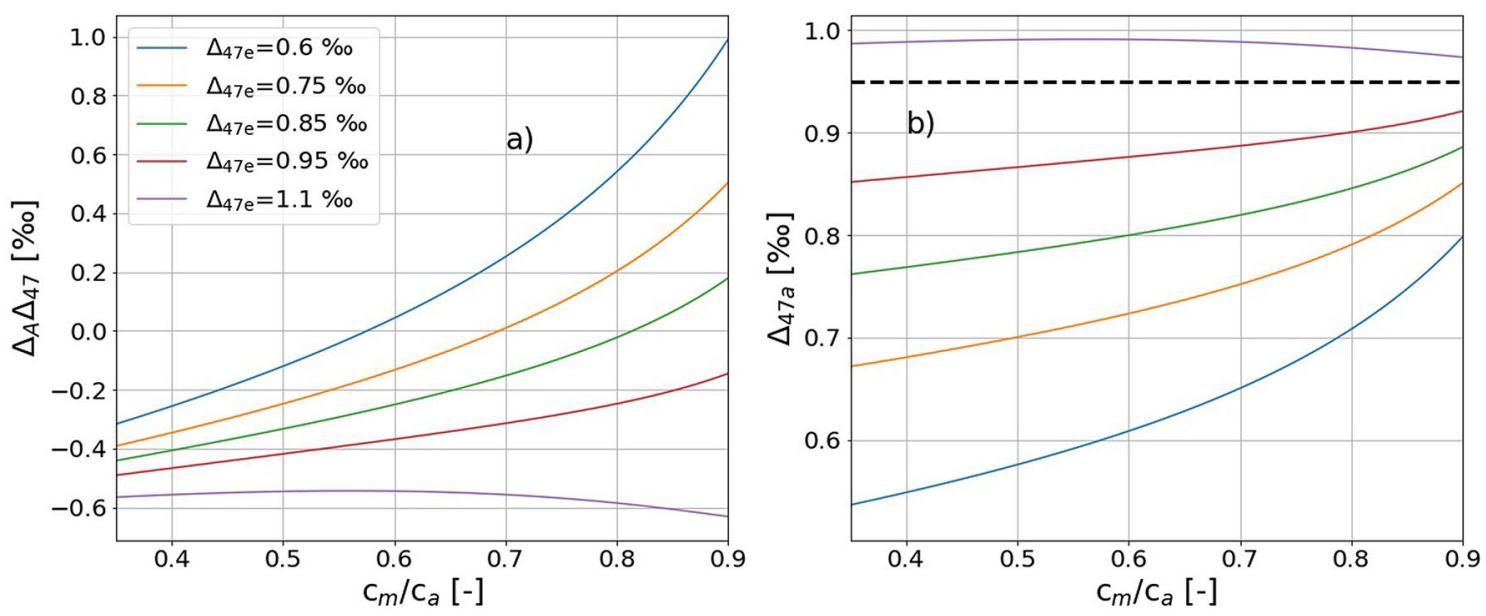

Figure 7. Leaf cuvette model result for $\Delta_{47}$ photosynthetic discrimination. (a) $\Delta_{\mathrm{A}} \Delta_{47}$ as a function of $c_{\mathrm{m}} / c_{\mathrm{a}}$ for various value of $\Delta_{47 \mathrm{e}}$ (see legend). Panel (b) shows the corresponding value for $\Delta_{47 \mathrm{a}}$, the black dashed line indicates the $\Delta_{47}$ of $\mathrm{CO}_{2}$ at the $\mathrm{CO}_{2}-\mathrm{H}_{2} \mathrm{O}$ exchange site for the leaf temperature of $20^{\circ} \mathrm{C}$.

$72 \mu \mathrm{mol} \mathrm{mol}{ }^{-1}$ (from 390 to 318 ) using Antirrhinum majus with a $c_{\mathrm{m}} / c_{\mathrm{a}}$ ratio of 0.85 , which is consistent with our results.

Using the leaf cuvette model, we quantitatively estimated the expected $\Delta_{47}$ discrimination based on the equations discussed in Sect. "Photosynthetic $\Delta_{47}$ discrimination" and the derived concentration gradient between the atmosphere and the site of $\mathrm{CO}_{2}-\mathrm{H}_{2} \mathrm{O}$ exchange $\left(c_{\mathrm{m}} / c_{\mathrm{a}}\right)$. For the $\mathrm{C}_{3}$ species, we obtained an excellent agreement between the observed and the predicted change in $\Delta_{47}$, except for one outlier for the experiments with Hedera (Fig. 6 and Figure S5). For Zea, the observed change between outgoing and ingoing $\mathrm{CO}_{2}$ of $-0.01 \pm 0.01 \%$ (the error is standard deviation for the three measurements) was slightly lower than the expected change in $\Delta_{47}$ of about $+0.01 \%$. However, the difference was still of the order of our measurement precession.

The correlation between $\Delta_{\mathrm{A}} \Delta_{47}$ and the $c_{\mathrm{m}} / c_{\mathrm{a}}$ ratio and the overall good agreement between observed and predicted $\Delta_{\mathrm{A}} \Delta_{47}$ confirm the hypothesis of Eiler and Schauble ${ }^{19}$ that $\mathrm{CO}_{2}-\mathrm{H}_{2} \mathrm{O}$ exchange and kinetic fractionation control the discrimination. For high $\mathrm{CO}_{2}$ back-diffusion fluxes, i.e., high $c_{\mathrm{m}} / c_{\mathrm{a}}$ ratios, the magnitude of the in- and outgoing $\mathrm{CO}_{2}$ flux is almost the same so that the kinetic term due to diffusion cancels out and the $\Delta_{47}$ value of the residual $\mathrm{CO}_{2}$ is close to the thermodynamic equilibrium value for the respective leaf temperature, i.e. $\Delta_{47}=0.95 \%$ at $20{ }^{\circ} \mathrm{C}$ (Fig. 2). At room temperature, the sensitivity of $\Delta_{47}$ to temperature is about $0.005 \%{ }^{\circ} /{ }^{\circ} \mathrm{C}$ so that small variations in temperature do not have a large effect. For $c_{\mathrm{m}} / c_{\mathrm{a}}$ ratios close to zero, the back-diffusion flux is small and the kinetic fractionation term due to diffusion into the intercellular airspace induces a negative discrimination in $\Delta_{47}$ of up to $-0.08 \%$ if the ingoing $\mathrm{CO}_{2}$ has a $\Delta_{47}$ close to $0 \%$.

As mentioned above and illustrated in Fig. 3, we used $\mathrm{CO}_{2}$ with an artificially diminished $\Delta_{47}$ value in the gas exchange experiments in order to increase the signal, i.e., the $\Delta_{47}$ difference between incoming and outgoing $\mathrm{CO}_{2}$. After having verified the Eiler and Schauble ${ }^{19}$ mechanism, we use our leaf cuvette model to quantify the effect of photosynthesis on $\Delta_{\mathrm{A}} \Delta_{47}$ for $\mathrm{CO}_{2}$ with typical ambient $\Delta_{47}$ values. In ambient air, $\Delta_{47}$ of $\mathrm{CO}_{2}$ is usually close to or lower than the $\Delta_{47}$ value of $\mathrm{CO}_{2}$ at the $\mathrm{CO}_{2}-\mathrm{H}_{2} \mathrm{O}$ exchange site $\left(\Delta_{47}=0.95 \%\right.$ ).

Figure 7 illustrates the calculated dependence of $\Delta_{\mathrm{A}} \Delta_{47}$, as well as $\Delta_{47 \mathrm{a}}$ on $c_{\mathrm{m}} / c_{\mathrm{a}}$ during gas exchange for $\Delta_{47 \mathrm{e}}$ values between $0.6 \%$ and $1.1 \%$ to get $\Delta_{47 \mathrm{a}}$ values between $0.6 \%$ and $1.05 \%$ close to the $\Delta_{47}$ values of atmospheric $\mathrm{CO}_{2}$ reported in literature ${ }^{19-22}$. A negative $\Delta_{\mathrm{A}} \Delta_{47}$ means that $47 \mathrm{a}<47 \mathrm{e}$ (Eq. 9), i.e., photosynthetic gas exchange would decrease ambient $\Delta_{47}$ values, whereas a positive $\Delta_{\mathrm{A}} \Delta_{47}$ would increase ambient $\Delta_{47}$ values. Figure 7a shows that $\Delta_{\mathrm{A}} \Delta_{47}$ is mostly negative, thus photosynthetic gas exchange generally acts to decrease $\Delta_{47}$ except for situations in which ambient $\Delta_{47}$ is at the low end of reported values and $c_{\mathrm{m}} / c_{\mathrm{a}}$ ratios are very high (indicating very slow assimilation rates).

At very low $c_{\mathrm{m}} / c_{\mathrm{a}}$ ratio, i.e., the diffusion limited case, $\Delta_{\mathrm{A}} \Delta_{47}$ is controlled by the diffusional fractionation. Figure $7 \mathrm{a}$ shows that $\Delta_{\mathrm{A}} \Delta_{47}$ converges to $-0.5 \%$ as $c_{\mathrm{m}} / c_{\mathrm{a}}$ approaches 0 , independent of the incoming $\mathrm{CO}_{2}$. As indicated in Fig. 2 , the theoretically calculated $\Delta_{47}$ fractionation associated with diffusion is $\Delta_{47 \mathrm{a}}-\Delta_{47 \mathrm{e}}=-0.3 \%$ o when all $\mathrm{CO}_{2}$ that enters the stomata is assimilated. In our leaf cuvette model where we assume a $\mathrm{CO}_{2}$ drawdown from 500 to $400 \mathrm{ppm}(\zeta=500 /(500-400)=5)$, this translates to $\left.\Delta_{\mathrm{A}} \Delta_{47} \approx \zeta \times\left(\Delta_{47 \mathrm{a}} \Delta_{47 \mathrm{e}}\right)=-1.5 \% \mathrm{o}\right)$. The fact that the model assumes that $2 / 3$ of the $\mathrm{CO}_{2}$ leave the stomata again without exchanging isotopes explains quantitatively why the diffusion limited endmember is $\zeta \times\left(\Delta_{47 \mathrm{a}-} \Delta_{47 \mathrm{e}}\right) / 3=-0.5 \%$, independent of the $\Delta_{47}$ of $\mathrm{CO}_{2}$ entering the cuvette. Figure $7 \mathrm{a}$ shows that in this limit the value of $\Delta_{47 \mathrm{a}}$ depends very strongly on $\Delta_{47 \mathrm{e}}$.

For the other extreme scenario $c_{\mathrm{m}} / c_{\mathrm{a}} \approx 1, \Delta_{47 \mathrm{a}}$ converges to the $\Delta_{47}$ value of $\mathrm{CO}_{2}$ at the $\mathrm{CO}_{2}-\mathrm{H}_{2} \mathrm{O}$ exchange site $\left(\Delta_{47}=0.95 \%\right.$ ) , independent of the $\Delta_{47}$ value of incoming $\mathrm{CO}_{2}$. This reflects the exchange dominated case in Fig. 2. In this case, $\Delta_{A} \Delta_{47}$ strongly depends on $\Delta_{47 \mathrm{e}}$ value of the $\mathrm{CO}_{2}$, for instance $\Delta_{\mathrm{A}} \Delta_{47}$ will be $\approx 0.00 \%$ and $\approx-0.75 \%$ for $\Delta_{47 \text { e }}$ of $0.95 \%$ and $1.1 \%$, respectively. This is similar to what Adnew et al. ${ }^{13}$ showed for the ${ }^{17} \mathrm{O}$-excess of $\mathrm{CO}_{2}$ in gas exchange experiments.

The leaf cuvette model calculations show that in principle photosynthetic gas exchange can deplete or enrich the $\Delta_{47}$ depending on the initial $\Delta_{47}$ value of the $\mathrm{CO}_{2}$ in the air surrounding the leaf, leaf temperature (via the $\Delta_{47}$ 
value at the exchange site) and the fraction of $\mathrm{CO}_{2}$ exchanged and diffused back to the atmosphere. However, photosynthesis will enrich $\Delta_{47}$ only if the $\Delta_{47}$ value of the $\mathrm{CO}_{2}$ entering the leaf is far lower than the $\Delta_{47}$ value of the $\mathrm{CO}_{2}$ at the $\mathrm{CO}_{2}-\mathrm{H}_{2} \mathrm{O}$ exchange site. In addition, Fig. $7 \mathrm{~b}$ shows that when $\Delta_{47 \mathrm{e}}$ is lower than the equilibrium value of $0.95 \%$, photosynthetic gas exchange cannot lead to $\Delta_{47 a}$ values above the equilibrium value. Thus, according to our leaf cuvette model, photosynthesis cannot lead to $\Delta_{47}$ values that are higher than the thermodynamic equilibrium (unless the incoming, i.e. ambient $\Delta_{47}$ values are already higher, in which case they would be reduced). This agrees well with most reported $\Delta_{47}$ values of atmospheric $\mathrm{CO}_{2}$ which are lower than expected from the $\mathrm{CO}_{2}-\mathrm{H}_{2} \mathrm{O}$ equilibrium at the surface temperature ${ }^{19-21}$.

As a result, an enrichment of up to $0.08 \%$ in $\Delta_{47}$ relative to the thermodynamic equilibrium value reported by Laskar and Liang ${ }^{22}$ for $\Delta_{47}$ measurements of $\mathrm{CO}_{2}$ sampled in a greenhouse cannot be explained by photosynthesis based on our leaf cuvette model results, even at the extreme scenario of $c_{\mathrm{m}} / c_{\mathrm{a}} \sim 1$. In addition, our results show that photosynthetic driven $\mathrm{CO}_{2}-\mathrm{H}_{2} \mathrm{O}$ isotope exchange affects $\Delta_{47}$ and $\delta^{18} \mathrm{O}$ in a similar way (Fig. 6, Figure S3 and S4) as observed for a simple $\mathrm{CO}_{2}-\mathrm{H}_{2} \mathrm{O}$ equilibration experiment ${ }^{32,33}$. This does not support the greenhouse experiment results of Laskar and Liang ${ }^{22}$ where they concluded that photosynthesis decouples $\delta^{18} \mathrm{O}$ and $\Delta_{47}$. We suggest that other processes than photosynthetic gas exchange affected the greenhouse gas experiments reported earlier ${ }^{22}$. Further experiments in similar environments should be carried out to investigate this in more detail.

Our results provide the experimental verification of the isotope exchange model suggested by Eiler and Schauble ${ }^{19}$. In particular, we determine how $\Delta_{\mathrm{A}} \Delta_{47}$ varies as a function of $c_{\mathrm{m}} / c_{\mathrm{a}}$. At high $c_{\mathrm{m}} / c_{\mathrm{a}}$ ratio (high backdiffusion flux), the effect of fractionation due to diffusion is negligible and the $\Delta_{47}$ of atmospheric $\mathrm{CO}_{2}$ will be driven towards the $\Delta_{47}$ of $\mathrm{CO}_{2}$ at the $\mathrm{CO}_{2}-\mathrm{H}_{2} \mathrm{O}$ exchange site. At low $c_{\mathrm{m}} / c_{\mathrm{a}}$ ratio, the diffusion fractionation dominates and photosynthetic gas exchange will generally lower $\Delta_{47}$. For the real atmosphere with $\Delta_{47}$ values slightly lower than the thermodynamic equilibrium set by $\mathrm{CO}_{2}-\mathrm{H}_{2} \mathrm{O}$ exchange, photosynthetic gas exchange cannot increase $\Delta_{47}$ above this equilibrium value.

Our results also show that $\Delta_{47}$ and ${ }^{18} \mathrm{O}$ discrimination are affected in similar ways during photosynthesis, but in contrast to ${ }^{18} \mathrm{O}$, the clumped isotope composition is independent of the $\delta^{18} \mathrm{O}$ of bulk leaf water. This means that it is not necessary to know the precise isotopic composition of water at the $\mathrm{CO}_{2}-\mathrm{H}_{2} \mathrm{O}$ exchange site for calculating $\Delta_{\mathrm{A}} \Delta_{47}$. Furthermore, a disequilibrium in $\Delta_{47}$ is often identified more readily than in $\delta^{18} \mathrm{O}$, since $\Delta_{47}$ depends mainly on $\mathrm{CO}_{2}-\mathrm{H}_{2} \mathrm{O}$ exchange temperature. As a result, measurements of $\Delta_{47}$ during air-leaf gas exchange experiments may be an alternative method to determine the mesophyll conductance to the site of $\mathrm{CO}_{2}-\mathrm{H}_{2} \mathrm{O}$ exchange and/or the degree of equilibration between $\mathrm{CO}_{2}-\mathrm{H}_{2} \mathrm{O}$ inside the leaf. The limitation to this approach is that the $\Delta_{47}$ signals are very small and it requires high precision measurements to constrain the relevant parameters significantly under ambient conditions.

For Helianthus, we found $g_{\mathrm{m} 13}$ values of $0.27 \pm 0.1 \mathrm{~mol} \mathrm{~m}^{-2} \mathrm{~s}^{-1} \mathrm{bar}^{-1}$ at a PPFD of $200 \mu \mathrm{mol} \mathrm{m}^{-2} \mathrm{~s}^{-1}$ $0.54 \pm 0.1 \mathrm{~mol} \mathrm{~m}^{-2} \mathrm{~s}^{-1} \mathrm{bar}^{-1}$ at a PPFD of $700 \mu \mathrm{mol} \mathrm{m} \mathrm{m}^{-2} \mathrm{~s}^{-1}$ and $0.43 \pm 0.05 \mathrm{~mol} \mathrm{~m}^{-2} \mathrm{~s}^{-1} \mathrm{bar}^{-1}$ at a PPFD of $1800 \mu \mathrm{mol} \mathrm{m}^{-2} \mathrm{~s}^{-1}$, in good agreement with values reported in previous studies ${ }^{41,43,67,68}$. These observations confirm earlier findings that the mesophyll conductance is generally lower at low light intensities (Flexas et al., 2007), although we did not observe any significant difference between mid and high light conditions. For Hedera, we found a $g_{\mathrm{m} 13}$ value of $0.20 \pm 0.02 \mathrm{~mol} \mathrm{~m}^{-2} \mathrm{~s}^{-1} \mathrm{bar}^{-1}$ at a PPFD of $700 \mu \mathrm{mol} \mathrm{m}^{-2} \mathrm{~s}^{-1}$, which is in good agreement with the maximum mesophyll conductance of $0.14 \pm 0.01 \mathrm{~mol} \mathrm{~m}^{-2} \mathrm{~s}^{-1} \mathrm{bar}^{-1}$ for evergreen angiosperms, including observations from the Hedera species ${ }^{41,43,51,69}$. The higher mesophyll conductance for Helianthus compared to Hedera might be due to the high mesophyll porosity and thin cell walls of mesophyll cells which facilitate easier movement of $\mathrm{CO}_{2}$ within intercellular airspaces and across cell walls as reported for evergreen woody plants ${ }^{70,71}$.

Mesophyll conductance $\left(g_{m 18}\right)$ of Helianthus did not show a clear dependency on PPFD (Table 1 and Figure S2) with on average a value of $0.68 \mathrm{~mol} \mathrm{~m}^{-2} \mathrm{~s}^{-1} \mathrm{bar}^{-1}$, which is in good agreement with the few values reported in the literature ${ }^{41,72}$. For maize, $g_{\mathrm{m} 18}=0.57 \mathrm{~mol} \mathrm{~m}^{-2} \mathrm{~s}^{-1} \mathrm{bar}^{-1}$, which is within the wide range of 0.169 to $0.9 \mathrm{~mol} \mathrm{~m}^{-2} \mathrm{~s}^{-1} \mathrm{bar}^{-1}$ reported in literature ${ }^{41,73-75}$. For Helianthus and Hedera, $g_{m 18}$ is on average 1.7 times $g_{m 13}$ confirming that $\mathrm{CO}_{2}-\mathrm{H}_{2} \mathrm{O}$ exchange occurs in the mesophyll cell, i.e., before the carboxylation site, in agreement with previous findings $s^{41,47,49,54}$.

\section{Data availability}

All the data used in this manuscript are presented in the form of Figures and Tables.

Received: 23 February 2021; Accepted: 15 June 2021

Published online: 07 July 2021

\section{References}

1. Affek, H. P. \& Yakir, D. The stable isotopic composition of atmospheric $\mathrm{CO}_{2} .2$ edn, 179-212 (Elsevier, 2014).

2. Ciais, P., Tans, P. P., Trolier, M., White, J. W. C., Francey, R. J. A large northern hemisphere terrestrial $\mathrm{CO}_{2}$ sink indicated by the ${ }^{13} \mathrm{C} /{ }^{12} \mathrm{C}$ ratio of atmospheric $\mathrm{CO}_{2}$ Science 269,4 (1995).

3. Ciais, P. et al. A three-dimensional synthesis study of $\delta^{18} \mathrm{O}$ in atmospheric CO2: 1 Surface fluxes. J. Geophys. Res. Atmos. 102, 5857-5872. https://doi.org/10.1029/96jd02360 (1997).

4. Cuntz, M., Ciais, P., Hoffmann, G. \& Knorr, W. A comprehensive global three-dimensional model of $\delta^{18} \mathrm{O}$ in atmospheric CO2: 1. Validation of surface processes. J. Geophys. Res. Atmos. 108, 24 (2003).

5. Cuntz, M. A dent in carbon's gold standard. Nature 477, 547-548 (2011).

6. Welp, L. R. et al. Interannual variability in the oxygen isotopes of atmospheric $\mathrm{CO}_{2}$ driven by El Niño. Nature 477, 579-582. https:// doi.org/10.1038/nature10421 (2011).

7. Adnew, G. A. et al. Determination of the triple oxygen and carbon isotopic composition of $\mathrm{CO}_{2}$ from atomic ion fragments formed in the ion source of the 253 Ultra High-Resolution Isotope Ratio Mass Spectrometer. Rapid Commun. Mass Spectrom. 33, 17 (2019).

8. Hoag, K. J., Still, C. J., Fung, I. Y. \& Boering, K. A. Triple oxygen isotope composition of tropospheric carbon dioxide as a tracer of terrestrial gross carbon fluxes. Geophys. Res. Lett. https://doi.org/10.1029/2004gl021011 (2005). 
9. Thiemens, M. K., Chakraborty, S. \& Jackson, T. L. Decadal $\Delta^{17} \mathrm{O}$ record of tropospheric $\mathrm{CO}_{2}$ : verification of a stratospheric component in the troposphere. J. Geophys. Res. Atmos. 119, 8 (2014).

10. Hofmann, M. E. G. et al. Atmospheric measurements of $\Delta^{17} \mathrm{O}$ in $\mathrm{CO}_{2}$ in Göttingen, Germany reveal a seasonal cycle driven by biospheric uptake. Geochim. Cosmochim. Ac. 199, 143-163. https://doi.org/10.1016/j.gca.2016.11.019 (2017).

11. Liang, M.-C., Mahata, S., Laskar, A. H., Thiemens, M. H. \& Newman, S. Oxygen isotope anomaly in tropospheric $\mathrm{CO}_{2}$ and implications for $\mathrm{CO}_{2}$ residence time in the atmosphere and gross primary productivity. Sci. Rep. 7, 13180. https://doi.org/10.1038/ s41598-017-12774-w (2017).

12. Koren, G. et al. Global 3-D Simulations of the Triple Oxygen Isotope Signature $\Delta^{17} \mathrm{O}$ in Atmospheric $\mathrm{CO}_{2}$. J. Geophys. Res. Atmos. 124, 28 (2019).

13. Adnew, G. A., Pons, T. L., Koren, G., Peters, W. \& Röckmann, T. Leaf-scale quantification of the effect of photosynthetic gas exchange on $\Delta^{17} \mathrm{O}$ of atmospheric $\mathrm{CO}_{2}$. Biogeosciences 17, 3903-3922 (2020).

14. Liang, M.-C. \& Mahata, S. Oxygen anomaly in near surface carbon dioxide reveals deep stratospheric intrusion. Sci. Rep. 5, 11352. https://doi.org/10.1038/srep11352 (2015).

15. Mahata, S., Chung-Ho, W., Bhattacharya, S. K. \& Mao-Chang, L. Near Surface $\mathrm{CO}_{2}$ triple oxygen isotope composition. Terrest. Atmos. Ocean. Sci. 27, 7 (2016).

16. Laskar, A. M., Mahata, S., Bhattacharya, S. K. \& Liang, M.-C. Triple oxygen and clumped isotope compositions of CO2 in the middle troposphere. Earth Space Sci. 6, 1205-1219 (2019).

17. Levin, I. a. K., Bernd and Schmidt, Martina and Sartorius, Hartmut. A novel approach for independent budgeting of fossil fuel $\mathrm{CO}_{2}$ over Europe by ${ }^{14} \mathrm{CO}_{2}$ observations. Geophys. Res. Lett., 2194 (2003).

18. Turnbull, J. C. et al. Assessment of fossil fuel carbon dioxide and other anthropogenic trace gas emissions from airborne measurements over Sacramento, California in spring 2009. Atmos. Chem. Phys. 11, 705-721 (2011).

19. Eiler, J. M. \& Schauble, E. ${ }^{18} \mathrm{O}^{13} \mathrm{C}^{16} \mathrm{O}$ in Earth's atmosphere. Geochim. Cosmochim. Acta 68, 10 (2004).

20. Affek, H. P. \& Eiler, J. M. Abundance of mass $47 \mathrm{CO}_{2}$ in urban air, car exhaust, and human breath. Geochim. Cosmochim. Acta. 70, 12. https://doi.org/10.1016/j.gca.2005.08.021 (2006).

21. Affek, H. P., Xu, X. \& Eiler, J. M. Seasonal and diurnal variations of ${ }^{13} \mathrm{C}^{18} \mathrm{O}^{16} \mathrm{O}$ in air: Initial observations from Pasadena CA. Geochim. Cosmochim. Acta 71, 5033-5043. https://doi.org/10.1016/j.gca.2007.08.014 (2007).

22. Laskar, A. H. \& Liang, M.-C. Clumped isotopes in near-surface atmospheric $\mathrm{CO}_{2}$ over land, coast and ocean in Taiwan and its vicinity. Biogeosciences 13, 7 (2016).

23. Röckmann, T., Popa, M. E., Krol, M. C. \& Hofmann, M. E. G. Statistical clumped isotope signatures. Sci. Rep. 6, 31947 (2016).

24. Wang, Z., Schauble, E. A. \& Eiler, J. M. Equilibrium thermodynamics of multiply substituted isotopologues of molecular gases. Geochim. Cosmochim. Acta. 68, 4779-4797 (2004).

25. Dennis, K. J., Affek, H. P., Passey, B. H., Schrag, D. P. \& Eiler, J. M. Defining an absolute reference frame for 'clumped'isotope studies of $\mathrm{CO}_{2}$. Geochim. Cosmochim. Acta 75, 7117-7131 (2011).

26. Affek, H. P., Xu, X. \& Eiler, J. M. Seasonal and diurnal variations of $13 \mathrm{C} 18 \mathrm{O} 16 \mathrm{O}$ in air: Initial observations from Pasadena CA. Geochim. Cosmochim. Acta 71, 10 (2007).

27. Francey, R. J. \& Tans, P. P. Latitudinal variation in oxygen-18 of atmospheric $\mathrm{CO}_{2}$. Nature 327, 2 (1987).

28. Farquhar, G. D. et al. Vegetation effects on the isotope composition of oxygen in atmospheric CO2. Nature 363, 439-443 (1993).

29. Gillon, J. S. \& Yakir, D. Influence of carbonic anhydrase activity in terrestrial vegetation on the ${ }^{18} \mathrm{O}$ content of atmospheric $\mathrm{CO}_{2}$ Science 291, 3 (2001).

30. Wingate, L. et al. The impact of soil microorganisms on the global budget of $\delta^{18} \mathrm{O}$ in atmospheric $\mathrm{CO}_{2}$. PNAS 106, 4 (2009).

31. Ogée, J., Wingate, L. \& Genty, B. Estimating mesophyll conductance from measurements of $\mathrm{C}^{18} \mathrm{OO}$ photosynthetic discrimination and carbonic anhydrase activity. Plant Physiol. 178, 728-752 (2018).

32. Affek, H. P. Clumped isotopic equilibrium and the rate of isotope exchange between $\mathrm{CO}_{2}$ and water. Am J. Sci. 313, 16. https://doi. org/10.2475/04.2013.02 (2013)

33. Clog, M., Stolper, D. \& Eiler, J. M. Kinetics of $\mathrm{CO}_{2}(\mathrm{~g})-\mathrm{H}_{2} \mathrm{O}$ (1) isotopic exchange, including mass 47 isotopologues. Chem. Geol. 395, 10 (2015)

34. Dai, A. Recent climatology, variability, and trends in global surface humidity. J. Clim. 19, 17 (2006).

35. Daëron, M., Blamart, D., Peral, M. \& Affek, H. P. Absolute isotopic abundance ratios and the accuracy of $\Delta_{47}$ measurements. Chem. Geol. 442, 13. https://doi.org/10.1016/j.chemgeo.2016.08.014 (2016).

36. Craig, H. Isotopic standards for carbon and oxygen and correction factors for mass-spectrometric analysis of carbon dioxide. Geochim Cosmochim Ac. 12, 16. https://doi.org/10.1016/0016-7037(57)90024-8 (1957).

37. Brand, W. A., Assonov, S. S. \& Coplen, T. B. Correction for the ${ }^{17} \mathrm{O}$ interference in $\delta^{13} \mathrm{C}$ measurements when analyzing $\mathrm{CO}_{2}$ with stable isotope mass spectrometry (IUPAC Technical Report). Pure Appl. Chem. 82, 1719-1733. https://doi.org/10.1351/pac-rep09-01-05 (2010).

38. Schauer, A. J., Kelson, J., Saenger, C. \& Huntington, K. W. Choice of ${ }^{17} \mathrm{O}$ correction affects clumped isotope $\left(\Delta_{47}\right)$ values of $\mathrm{CO}_{2}$ measured with mass spectrometry. Rapid Commun. Mass Spectrom. 30 (2016).

39. Ubierna, N. et al. Critical review: incorporating the arrangement of mitochondria and chloroplasts into models of photosynthesis and carbon isotope discrimination. Photosynth. Res. 141, 26 (2019).

40. Cousins, A. B., Mullendore, D. L., Sonawane, B. V. Recent developments in mesophyll conductance in $\mathrm{C}_{3}, \mathrm{C}_{4}$ and CAM plants Plant J. 101, 816-830 (2020).

41. Adnew, G. A. The effect of photosynthetic gas exchange on $\Delta{ }^{17} \mathrm{O}$ of atmospheric $\mathrm{CO}_{2}$. PhD thesis. doi:https://doi.org/10.33540/ $412(2020)$.

42. Farquhar, G. D., Ehleringer, J. R. \& Hubick, K. T. Carbon isotope discrimination and photosynthesis. Annu. Rev. Plant Physiol. Plant Mol. Biol. 40, 503-537 (1989).

43. Flexas, J., Ribas-Carbo, M., Diaz-Espejo, A., Galmes, J. \& Medrano, H. Mesophyll conductance to $\mathrm{CO}_{2}$ : current knowledge and future prospects. Plant Cell Environ. 31, 19 (2008).

44. Busch, F. A., Holloway-Phillips, M., Stuart-Williams, H. \& Farquhar, G. D. Revisiting carbon isotope discrimination in $\mathrm{C}_{3}$ plants shows respiration rules when photosynthesis is low. Nat. Plants 6, 245-258 (2020).

45. Farquhar, G. D. \& Richards, R. A. Isotopic composition of plant carbon correlates with water-use efficiency of wheat genotypes. Funct. Plant Biol. 11, 11 (1984).

46. Farquhar, D. G. \& Lloyd, J. Carbon and oxygen isotope effects in the exchange of carbon dioxide between terrestrial plants and the atmosphere. 33 (Acadamic Press Inc., 1993).

47. Barbour, M. M., Evans, J. R., Simonin, K. A. \& Caemmerer, S. v. Online $\mathrm{CO}_{2}$ and $\mathrm{H}_{2} \mathrm{O}$ oxygen isotope fractionation allows estimation of mesophyll conductance in $\mathrm{C}_{4}$ plants, and reveals that mesophyll conductance decreases as leaves age in both $\mathrm{C}_{4}$ and $\mathrm{C}_{3}$ plants. New Phytol., 875-889 (2016).

48. Evans, J. R., Sharkey, T. D., Berry, J. A. \& Farquhar, G. D. Carbon isotope discrimination measured concurrently with gas exchange to investigate $\mathrm{CO}_{2}$ diffusion in leaves of higher plants. Funct Plant. Biol. 13, 11 (1986).

49. Gillon, J. S. \& Yakir, D. Internal conductance to $\mathrm{CO}_{2}$ diffusion and $\mathrm{C}^{18} \mathrm{OO}$ discrimination in $\mathrm{C}_{3}$ leaves. Plant Physiol. 123, 13 (2000).

50. Caemmerer, S. v., Ghannoum, O., Pengelly, J. J. L. \& Cousins, A. B. Carbon isotope discrimination as a tool to explore $\mathrm{C}_{4}$ photosynthesis. J. Exp. Bot. 65, 3459 (2014). 
51. Pons, T. L. et al. Estimating mesophyll conductance to $\mathrm{CO}_{2}$ : methodology, potential errors, and recommendations. J. Exp. Bot. 60, 7 (2009).

52. Holloway-Phillips, M., Cernusak, L. A., Stuart-Williams, H., Ubierna, N. \& Farquhar, G. D. Two-source $\delta^{18} \mathrm{O}$ method to validate the $\mathrm{CO}^{18} \mathrm{O}$-photosynthetic discrimination model: implications for mesophyll conductance. Plant Physiol. 181, 15 (2019).

53. Cernusak, L. A., Farquhar, G. D., Wong, S. C. \& Stuart-Williams, H. Measurement and interpretation of the oxygen isotope composition of carbon dioxide respired by leaves in the dark. Plant Physiol. 136, 13 (2004).

54. Gillon, J. S. \& Yakir, D. Naturally low carbonic anhydrase activity in $\mathrm{C}_{4}$ and $\mathrm{C}_{3}$ plants limits discrimination against $\mathrm{C}^{18} \mathrm{OO}$ during photosynthesis. Plant Cell Environ. 23, 12 (2000).

55. Song, X., Simonin, K. A., Loucos, K. E. \& Barbour, M. M. Modelling non-steady-state isotope enrichment of leaf water in a gasexchange cuvette environment. Plant Cell Environ. 38, 10 (2015).

56. Parkinson, K. J. A simple method for determining the boundary layer resistance in leaf cuvettes. Plant Cell Environ 8, 223-226 (1985).

57. Laskar, A. H., Mahata, S. \& Liang, M.-C. Identification of anthropogenic $\mathrm{CO}_{2}$ using triple oxygen and clumped isotopes. Environ. Sci. Technol. 50, 18. https://doi.org/10.1021/acs.est.6b02989 (2016).

58. Defliese, W. F. \& Lohmann, K. C. Non-linear mixing effects on mass- $47 \mathrm{CO}_{2}$ clumped isotope thermometry: patterns and implications. Rapid Commun. Mass Spectrom. 29, 901-909 (2017).

59. Koren, G., Adnew, G. A., Röckmann, T. \& Peters, W. Leaf conductance model for ${ }^{17} \mathrm{O}$ in $\mathrm{CO}_{2}$, https://git.wur.nl/leaf_model. (2020).

60. Pons, T. L. \& Welschen, R. A. M. Technical report; Overestimation of respiration rates in commercially available clamp-on leaf chambers. Complications with measurement of net photosynthesis. Plant, Cell Environ. 25, 1367-1372. https://doi.org/10.1093/ jxb/erp081 (2002).

61. von Caemmerer, S. \& Farquhar, G. D. Some relationships between the biochemistry of photosynthesis and the gas exchange of leaves. Planta 153, 376-387 (1981).

62. Werner, R. A., Rothe, M. \& Brand, W. A. Extraction of $\mathrm{CO}_{2}$ from air samples for isotopic analysis and limits to ultra high precision $\delta^{18} \mathrm{O}$ determination in $\mathrm{CO}_{2}$ gas. Rapid Commun. Mass Spectrom. 15, 2152-2167 (2001).

63. Werner, R. A. \& Brand, W. A. Referencing strategies and techniques in stable isotope ratio analysis. Rapid Commun Mass Spectrom 15, 501-519. https://doi.org/10.1002/rcm.258 (2001)

64. Huntington, K. W. et al. Methods and limitations of 'clumped'CO $\mathrm{O}_{2}$ isotope $\left(\Delta_{47}\right)$ analysis by gas-source isotope ratio mass spectrometry. J. Mass Spectrom. 44, 11 (2009).

65. Cernusak, L. A. et al. Stable isotopes in leaf water of terrestrial plants. Plant Cell Environ. 39, 1087-1102. https://doi.org/10.1111/ pce.12703 (2016).

66. Farquhar, G. D., Cernusak, L. A. \& Barnes, B. Heavy water fractionation during transpiration. Plant Physiol. 143, 7 (2007).

67. Hanba, Y. T., Kogami, H. \& Terashima, I. The effect of internal CO2 conductance on leaf carbon isotope ratio. Isotopes Environ. Health Stud 39, 5-13. https://doi.org/10.1080/1025601031000102233 (2003).

68. Laisk, A. \& Loreto, F. Determining photosynthetic parameters from leaf CO2 exchange and chlorophyll fluorescence (ribulose-1, 5-bisphosphate carboxylase/oxygenase specificity factor, dark respiration in the light, excitation distribution between photosystems, alternative electron transport rate, and mesophyll diffusion resistance. Plant Physiol. 110, 9 (1996).

69. Loreto, F., Harley, P. C., Marco, G. D. \& Sharkey, T. D. Estimation of mesophyll conductance to $\mathrm{CO}_{2}$ flux by three different methods. Plant Physiol. 98, 6 (1992).

70. Veromann-Jürgenson, L.-L., Tosens, T., Laanisto, L. \& Niinemets, ü. Extremely thick cell walls and low mesophyll conductance: welcome to the world of ancient living!. Journal of Experimental Botany 68 (2017).

71. Niinemets, Ü. Does the touch of cold make evergreen leaves tougher?. Tree Physiol. 36, 5 (2016).

72. Shrestha, A., Song, X. \& Barbour, M. M. The temperature response of mesophyll conductance, and its component conductances, varies between species and genotypes. Photosynth. Res., 18 (2019).

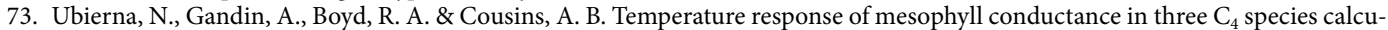
lated with two methods: ${ }^{18} \mathrm{O}$ discrimination and in vitro Vpmax. New Phytol. 214, 66-80 (2017).

74. Kolbe, A. R. \& Cousins, A. B. Mesophyll conductance in Zea mays responds transiently to $\mathrm{CO}_{2}$ availability: implications for transpiration efficiency in $\mathrm{C}_{4}$ crops. New Phytol. 217, 11 (2018).

75. Ubierna, N., Gandin, A. \& Cousins, A. B. The response of mesophyll conductance to short-term variation in $\mathrm{CO}_{2}$ in the $\mathrm{C}_{4}$ plants Setaria viridis and Zea mays Journal of experimental botany 69, 11 (2018).

\section{Acknowledgements}

GAA is supported by EU Horizon 2020 ERC-ASICA project with a research grant number 64908 and project ALWPP.2016.013 of the Dutch Science Foundation NWO. GK is supported by EU Horizon 2020 ERC-ASICA project with a research grant number 649087. MEGH supported by Dutch Science Foundation NWO with Grant Number 822.01.014 for clumped isotopes in atmospheric $\mathrm{CO}_{2}$ project.

\section{Author contributions}

M.E.G.H. and T.R. designed the experiment, T.P. and M.E.G.H. performed the leaf cuvette experiment and air sampling. G.A.A., T.P., M.E.G.H. and T.R. evaluated the data. G.K. provided the leaf cuvette model calculations. G.A.A., M.E.G.H. and T.R. wrote the manuscript with contributions from T.P., G.K., M.Z., and L.J.L.

\section{Competing interests}

The authors declare no competing interests.

\section{Additional information}

Supplementary Information The online version contains supplementary material available at https://doi.org/ 10.1038/s41598-021-93092-0.

Correspondence and requests for materials should be addressed to G.A.A.

Reprints and permissions information is available at www.nature.com/reprints.

Publisher's note Springer Nature remains neutral with regard to jurisdictional claims in published maps and institutional affiliations. 
(c) (i) Open Access This article is licensed under a Creative Commons Attribution 4.0 International cc) License, which permits use, sharing, adaptation, distribution and reproduction in any medium or format, as long as you give appropriate credit to the original author(s) and the source, provide a link to the Creative Commons licence, and indicate if changes were made. The images or other third party material in this article are included in the article's Creative Commons licence, unless indicated otherwise in a credit line to the material. If material is not included in the article's Creative Commons licence and your intended use is not permitted by statutory regulation or exceeds the permitted use, you will need to obtain permission directly from the copyright holder. To view a copy of this licence, visit http://creativecommons.org/licenses/by/4.0/.

(C) The Author(s) 2021 